\title{
Fault diagnosis for engine air path with neural models and classifier
}

\author{
Adnan Hamad $^{1}$, Dingli $\mathbf{Y u}^{1}$, J. B. Gomm ${ }^{1}$, Mahavir S. Sangha ${ }^{2}$ \\ ${ }^{1}$ Control System Research Group, School of Engineering, Liverpool John Moores University, Byrom Street, Liverpool L3 3AF, U.K \\ ${ }^{2}$ Test Technology \& Emissions, Cummins Inc., Daventry NN11 8NU, U.K \\ Correspondence authord.yu@ljmu.ac.uk
}

\begin{abstract}
Fault detection and isolation (FDI) have become one of the most important aspects of automobile design. A new FDI scheme is developed for automotive engines in this paper. The method uses an independent radial basis function (RBF) neural network model to model engine dynamics, and the modelling errors are used to form the basis for residual generation. A dependent RBFNN model is a model which uses output data of a plant as a target output then use it to train the neural network, while, The independent RBFNN model is a higher accuracy than the dependent model and the errors can be detected by this model, because this model does not dependent on the output of the plant and it will use its output as a target, so if any faults in the plant will be not effect in the model and this faults will be detected easily and clearly. Furthermore, another RBF network is used as a fault classifier to isolate different faults from the modelling errors. The method is developed and the performance assessed using the engine benchmark, the Mean Value Engine Model (MVEM) with Matlab/Simulink. Five faults have been simulated on the MVEM, including three sensor faults, one component fault and one actuator fault. The three sensor faults considered are 10-20\% changes superimposed on the measured outputs of manifold pressure, manifold temperature and crankshaft speed sensors; one component fault considered is air leakage in intake manifold; the actuator fault considered is the malfunction of fuel injector. The simulation results show that all the simulated faults can be clearly detected and isolated in dynamic conditions throughout the engine operating range.
\end{abstract}

Keywords: Automotive engines, independent RBF model, RBF neural networks, fault detection, fault isolation.

DOI: http://dx.doi.org/10.4314/ijest.v3i8.6

\section{Introduction}

A fault is defined as any type of malfunction of components, which may happen in a system and this fault will degrade the system performance but not cause catastrophe. Fault detection is the procedure which informs us that something is wrong in the system and needs to be repaired. Moreover, fault isolation is to determine which fault occurs among the possible faults. Over the last few years, many different fault detection and isolation methods have been proposed.

FDI for automotive engines has been investigated for more than two decades. Yu and Rizzoni (1991) have introduced architecture for a special purpose diagnostic processor, designed specifically to interact as a co-processor with the on-board controller(s). The processor considered the structure of model-based failure detection algorithms and the need for simulating the dynamics of vehicle subsystems in order to monitor their performance, and processes the information provided by on-board sensors to diagnose sensor or actuator malfunctions. The diagnostic information is available both to the controller for possible system reconfiguration, and to repair technicians for service bay applications. Blanke et al. (1995) introduced an electromechanical position servo, used in the speed control of large diesel engines, as a benchmark for mode-based fault detection and identification (FDI). The benchmark is based on a test facility built by the authors. The equipment simulates the actuators part of a speed governor for large diesel engine. The governor is a device that controls the shaft rotational speed on a diesel engine. The paper has provided a simple mathematical model of this system for use in the design of fault handling methods and a complete nonlinear description for simulation and verification work. A model based diagnosis system for the air path of a turbo charged 
diesel engine with exhaust gas recirculation (EGR) was constructed by Nyberge et al. (2004). The faults considered were air mass flow sensor fault, intake manifold pressure sensor fault, air leakage, and the EGR valve stuck in closed position. The design of the diagnosis system then follows the framework of structured hypothesis tests. It has been shown this framework is a useful engineering tool to systematically design model based diagnosis systems.

Isermann (2005) has proposed Model-based fault-detection and diagnosis methods for some technical processes. The goal was to generate several symptoms indicating the difference between nominal and faulty status. Based on different symptoms fault diagnosis procedures follow, determining the fault by applying classification or inference methods. His contribution gave a short introduction into the field and showed some applications for an actuator, a passenger car and a combustion engine. For fault diagnosis of diesel engines three detection modules are proposed to generate symptoms based on mainly production- type sensors. The symptoms are generated with nonlinear output error and input error parity equations for special model-based characteristic quantities like volumetric efficiency, oscillations of pressure, flow and for angular speed and oxygen content.

The implementation of an instrument fault detection, isolation and accommodation (IFDIA) scheme developed for real time automotive applications was studied by Capriglione et al. (2005). The realized scheme was able to identify and accommodate different kind of faults: short circuit, open circuit, uncalibration and hold. Moreover the scheme is characterized by good performance also in terms of promptness and sensitivity: short and open circuit faults are located in $1 \mathrm{~s}$, while "small" faults as uncalibration and old require a grater observation time up to $180 \mathrm{~s}$. In many critical applications like nuclear plants, aircrafts, space vehicles and chemical processes, the use of fault tolerant measurement systems is strongly required. Thus, the hardware and/or software instrument fault detection, isolation and accommodation (IFDIA) schemes are more and more widespread in many contexts. Automotive is one of these, since in the last decade, private and public transportation vehicles have been equipped with a lot of sensor-based electronic systems devoted to grant the passenger safety and comfort (Anti-lock braking system, Anti-spin regulation, Electronic stability program, Airbag, air conditioning, and so on) as well as to control fuel injection and ignition and the pollution emissions of the engines. On-line Sensor fault Detection, isolation, and accommodation in automotive engines had studied by Capriglione et al. (2004). Their paper described the hybrid solution, based on artificial neural networks (ANNs), and the production rule adopted in the realization of an instrument fault detection, isolation, and accommodation scheme for automotive applications. The fault accommodation has shown a good performance with maximum error of $5 \%$.

Fault detection for modern Diesel engines using signal- and process model-based methods have been proposed by Kimmich et al. (2005). Their contribution showed a systematic development of fault detection and diagnosis methods for two system components of diesel engines, the intake system and the injection system together with the combustion process. The residuals were generated by applied semiphysical dynamic process models, identification with special neural networks, signal models and parity equations. The deflection of the residuals allowed the detection and diagnosis of different faults. Further residuals were developed for the exhaust system. The additional symptoms increase the fault detection coverage. Tan et al. (2005) have used the external recurrent neural networks to identify nonlinear dynamic models for the manifold pressure and the mass air flow processes in automotive engines. Dynamic Levenberg-Marquardt algorithm was applied to the weight-estimation problem. Experimental results showed that the neural-network-based models are more precise and generalized in performance than the first-principles based models. Robustness assessment and adaptive FDI for car engine was investigated by Sangha et al. (2008).

A new on-line fault detection and isolation (FDI) scheme proposed for engines using an adaptive neural network classifier is evaluated for a wide range of operational modes to check the robustness of the scheme in their paper. Robustness assessment has been carried out against fixed and sinusoidal throttle angle inputs, change in load, change in engine parameter, and all these changes occurring at the same time for both adaptive and non-adaptive networks. Wu et al. (2009) in their paper had proposed an expert system for fault diagnosis system in internal combustion engines using wavelet packet transform (WPT) and artificial neural network (ANN) techniques. To verify the effect of the proposed generalized regression neural network (GRNN) in fault diagnosis, a conventional back-propagation network (BPN) was compared with a GRNN network. The experimental results showed the proposed system achieved an average classification accuracy of over $95 \%$ for various engine working conditions. Because a neural network is capable of approximating a nonlinear function to any desired degree of accuracy, it is used as a model of a dynamic system. The modelling error is then used as the residual for fault detection. Furthermore, a neural network can also be trained to isolate different faults. Timo Sorsa et al. (1991) investigated a number of possible neural network architectures for fault diagnoses. The multilayer perceptron network with a hyperbolic tangent as the nonlinear element was reported to be best suited for the task.

$\mathrm{Yu}$ et al. (1998) proposed Radial basis function (RBF) neural networks for process fault diagnosis. The use of the output prediction error, between a neural network model and a non-linear dynamic process, as a residual for diagnosing actuator, component and sensor faults was analysed. Jamsa-Jounela et al. (2003) had described a fault diagnosis system and discussed some application results from the Outokumpu Harjavalta smelter. M. Demetgul et al. (2009) investigated fault diagnosis of pneumatic systems with artificial neural network algorithms. A pneumatic manufacturing system was simulated with modular production system (MPS) and automated monitoring of the system was considered. Artificial neural networks provide an excellent mathematical tool for dealing with non-linear problems. They are especially useful in situations when there is no mathematical model of the process considered, so the classical approaches such as observers or parameter estimation methods cannot be applied. In this paper, to detect faults, the output of the real system (MVEM) was compared with the output of an independent RBF neural network model of the engine. The modelling error is then used as the residual for fault detection. Moreover, another neural network is trained as a classifier to isolate different faults using residual vector. The K-means clustering algorithm is used to 
choose the centres of RBFNN. Recursive least square (RLS) the algorithm is used to update for each new sample the parameter matrix W.

\section{Mean Value Engine Model (MVEM)}

The engine model adopted in this study is the mean value engine model developed by Elbert Hendricks (2000), which is a widely used benchmark for engine modelling and control. The platform which has been selected for MVEM is the popular MATLAB/SIMULINK. The mean value engine model has three sub-systems; manifold filling dynamics, crankshaft speed dynamics and Fuel injection dynamics (see Figure 1).

\subsection{Major Engine Control Variables}

Due to the increasing requirements of governments and customers, the main objective of SI engine development is to generate a power output as high as possible, while at the same time keeping fuel consumption and exhaust emissions down to a minimum in order to comply with the requirements of emissions-control legislation. To satisfy these requirements, many variables such as engine speed, engine torque, ignition angle, injection timing, emission gas and so on need to be controlled. It is very difficult to achieve satisfactory control performance for these variables because they are severely non-linear and complicatedly related to each other. Moreover, car engines have several different operating modes including start up, idle, running and braking. Therefore, engine dynamics are highly non-linear and multivariable, which makes engine control problems more complex and difficult (S. W. Wang et al, 2006 and Balluchi, et al,2000).

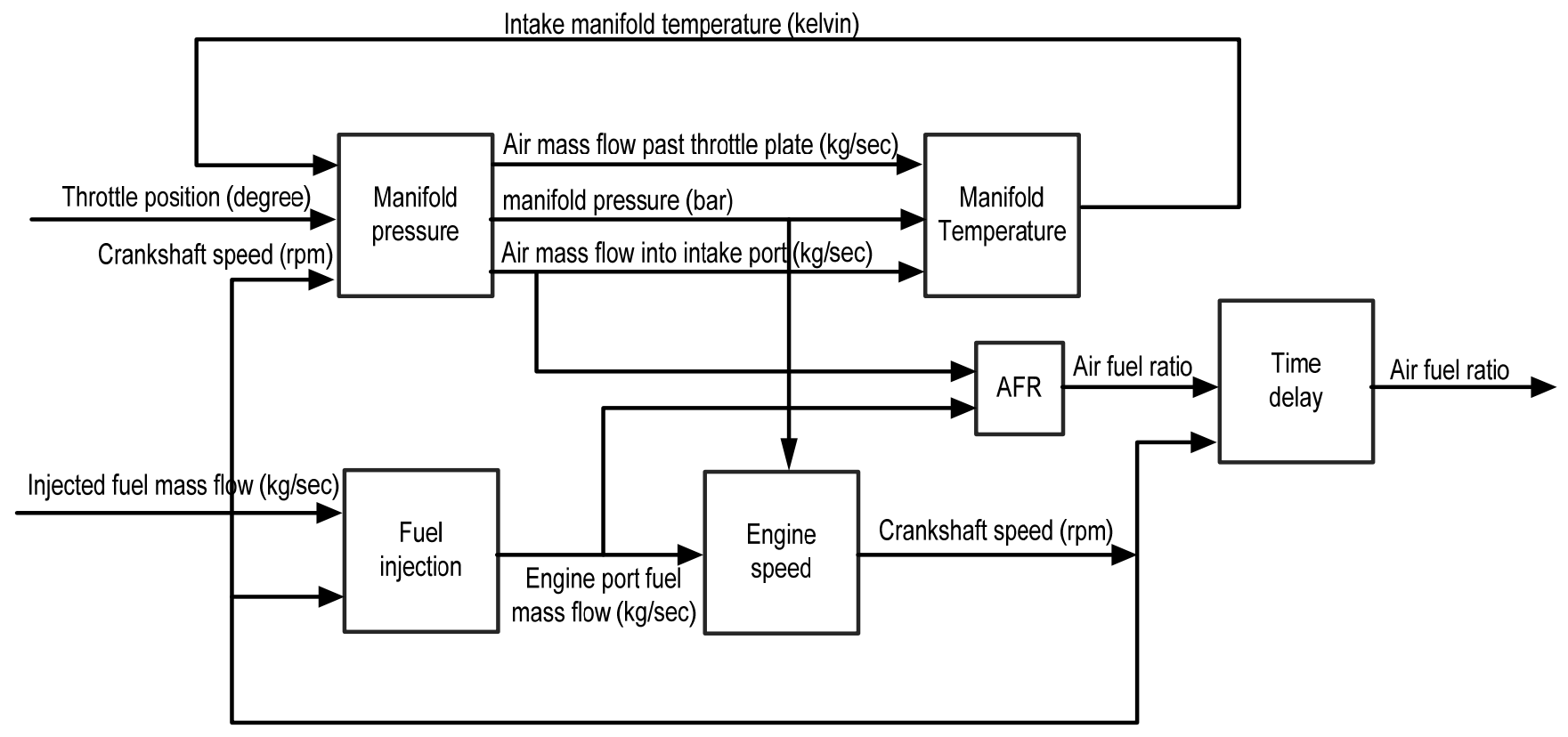

Fig.1 Mean value engine model

\subsection{Manifold Filling Dynamics}

It includes two nonlinear differential equations: one for the manifold pressure and the other for the manifold temperature. The manifold pressure is described as

$$
\dot{p}_{i}=\frac{T_{i} R}{V_{i}}\left(-\dot{m}_{a p}+\dot{m}_{a t}+\dot{m}_{E G R}\right)
$$

Where $\dot{p}_{i}$ is absolute manifold pressure (bar), $\dot{m}_{a t}$ is air mass flow past throttle plate $(\mathrm{kg} / \mathrm{sec}), \dot{m}_{a p}$ is air mass flow into intake port $(\mathrm{kg} / \mathrm{sec})$, $\boldsymbol{n}_{\mathrm{C}}^{\mathrm{C} g \mathrm{R}}$ is EGR mass flow $(\mathrm{kg} / \mathrm{sec}), T_{i}$ is intake manifold temperature in Kelvin, $V_{i}$ is (manifold \& port passage) volume $\left(\mathrm{m}^{3}\right)$ and $R$ is gas constant $\left(287 \times 10^{-5}\right)$. The manifold temperature dynamics are described by the differential equation (Hendricks, et al, 2000). 


$$
\dot{T}_{i}=\frac{T_{i} R}{P_{i} V_{i}}\left[-\dot{m}_{a p}(k-1) T_{i}+\dot{m}_{a t}\left(k T_{a}-T_{i}\right)+\dot{m}_{E G R}\left(k T_{E G R}-T_{i}\right)\right]
$$

\subsection{Crankshaft Speed Dynamic}

The crankshaft dynamics is derived using conservation of rotational energy on the crankshaft (Hendricks, et al, 2000).

$$
\dot{n}=-\frac{1}{I n}\left(P_{f}\left(p_{i}, n\right)+P_{p}\left(p_{i}, n\right)+P_{b}(n)\right)+\frac{1}{I n} H_{u} \eta_{i}\left(p_{i}, n, \lambda\right) m_{f}\left(t-\Delta_{\tau} d\right)
$$

Both the friction power $P_{f}$ and the pumping power $P_{p}$ are related with the manifold pressure pi and the crankshaft speed $n$. The load power $P_{b}$ is a function of the crankshaft speed $n$ only. The volumetric efficiency $\eta_{i}$ is a function of the manifold pressure $p_{i}$, the crankshaft speed $n$ and the air/fuel ratio $A F R$. Where $I$ is the scaled moment of inertia of the engine and its load and where the mean injection/torque time delay has been taken into account with the variable $\Delta \tau_{d}$.

\subsection{Fuel injection dynamics}

According to the identification experiments with an SI engine carried out by Hendricks et al. (Hendricks, et al, 2000), the fuel flow dynamics could be described as

$$
\begin{aligned}
& \frac{d m_{f f}}{d t}=\frac{1}{\tau_{f}}\left(-\dot{m}_{f f}+X_{f} \dot{m}_{f i}\right) \\
& \dot{m}_{f v}=\left(1-X_{f}\right) \dot{m}_{f i} \\
& \dot{m}_{f}=\dot{m}_{f v}+\dot{m}_{f f}
\end{aligned}
$$

Where $\frac{d m f f}{d t}$ is fuel film mass flow, $\dot{m}_{f i}$ is injected fuel mass flow, $\dot{m}_{f v}$ is fuel vapor mass flow. The model is based on keeping track of the fuel mass flow. The parameters in the model are the time constant $\tau_{f}$ for fuel evaporation, and the proportion $X_{f}$ of the fuel which is deposited on the intake manifold or close to the intake valves.

\section{Engine modelling using RBF neural network}

The first step in the engine modelling by using RBFNN is the generation of a suitable training data set. As the training data will influence the accuracy of the neural network modelling performance, the objective of experiment design on training data is to make the measured data become maximally informative, subject to constraints that may be at hand. A set of random amplitude signals (RAS) were designed for the throttle angle position and the fuel mass flow to obtain a representative set of input data. The ranges of these excitation signals were bounded between 20 and 60 degrees for the throttle angle position and between 0.0005 and $0.003 \mathrm{~kg} / \mathrm{s}$ for the fuel mass flow. The first 300 samples of excitation signals for the throttle angle position is shown in Figures 2 as an example. At the beginning the first RBF neural network will be trained and tested. It will receive five inputs signals, which are manifold pressure, temperature, crankshaft speed, the throttle angle and the fuel mass flow and has three outputs, manifold pressure, temperature, crankshaft speed. By using K-means algorithm and $p$ - Nearest Neighbours method the width in hidden layer nodes of the RBF neural network $\sigma$ and the centres $c$ are calculated. For training the weights $w$ of the RBF neural networks, the recursive least square algorithm was applied and the best results were found when the following data was used: $\mu=0.98, w(0)$ $=1.0 \times 10^{-6} \times U_{(n h \times 3),} P(0)=1.0 \times 10^{8} \times I_{(\mathrm{nh})}$. Where $I$ is an identity matrix and $U$ is an ones matrix. The neural network model will use only the first three rows of the MVEM output matrix which are contain values of manifold pressure, manifold temperature and crankshaft speed, after that the output of the neural network will be fed back and used as training data for this neural network. The engine data was divided into two parts, the first 4000 data set is used for training neural network and the 2000 data samples is used for neural network model validation, This procedure in order to confirm validity of the neural network model. The Figure 3 a, $b$ and $\mathrm{c}$ shows the simulation result of the engine model output and the RBF neural network output during the 100 samples for training and 100 samples for test. It can be seen that the good match between the two outputs with a very small error, in general. The modelling error of the training data set is often smaller than the test data set. The mean absolute error (MAE) was used to evaluate the modelling. For this model the MAE values of crankshaft speed, manifold pressure and temperature are $0.0014,0.013$ and 0.0047 respectively. 


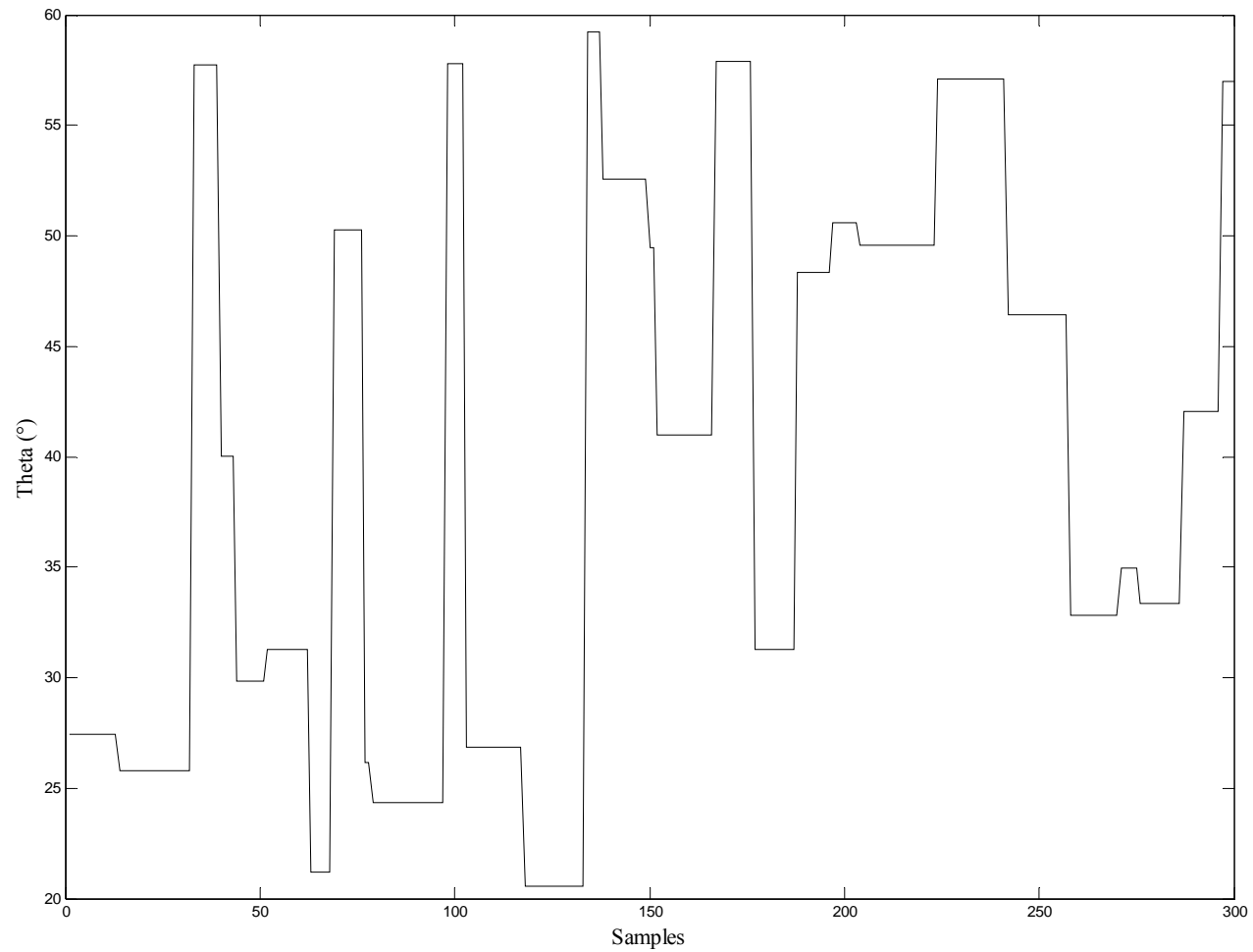

Figure 2. Random Amplitude Signal of the Throttle Angle Position.

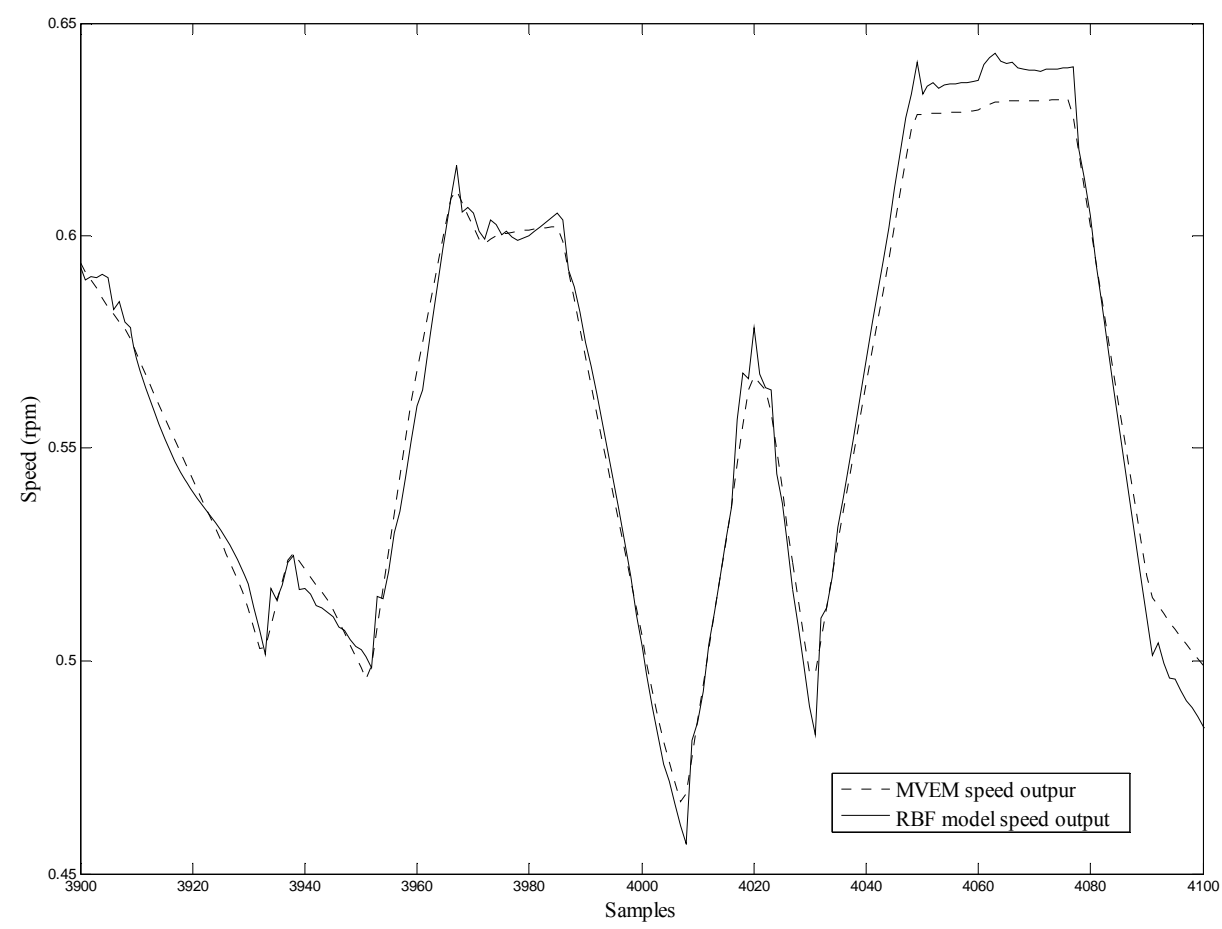

(a) 


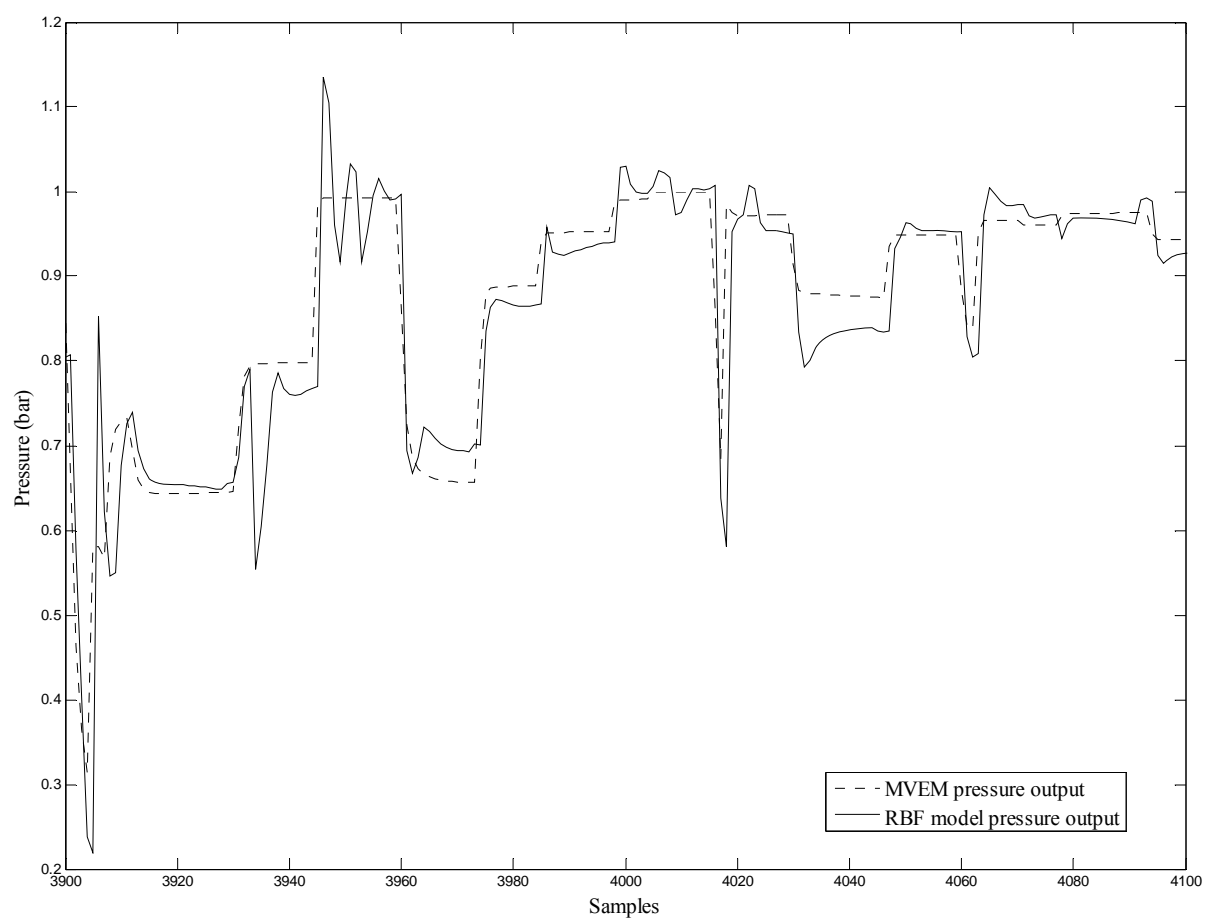

(b)

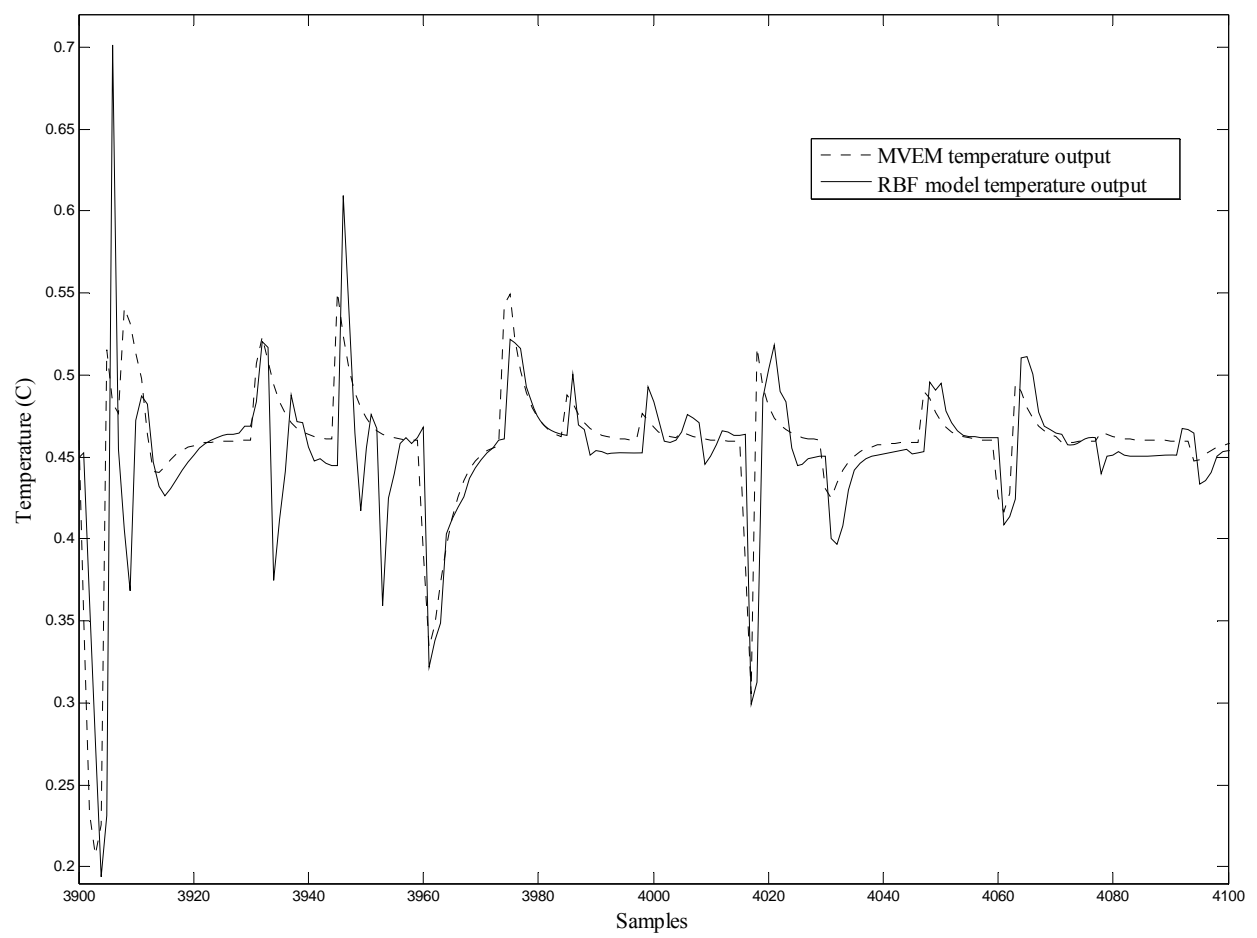

(c)

Figure 3, a, b and c. The simulation result of the speed, pressure and temperature engine model output and the RBF neural networks output respectively. 


\section{Fault simulation}

One component, one actuator and three sensor faults with different levels of intensity have been investigated as practical examples of SI engine faults. The component fault is air leakage in the intake manifold. The actuator fault is injected fuel mass flow. The three sensor faults are intake manifold pressure, temperature and speed. Details of the simulation of the faults are described in the following subsections.

A. Air leakage Fault: To collect the engine data subjected to the air leakage fault, equation (1) of the manifold pressure is modified to equation (7):

$$
\dot{p}_{i}=\frac{T_{i} R}{V_{i}}\left(-\dot{m}_{a p}+\dot{m}_{a t}+\dot{m}_{E G R}-\Delta l\right)
$$

Where $\Delta l$ is used to simulate the leakage from the air manifold, which is subtracted to increase the air outflow from the intake manifold. $\Delta l=0$ will represent no air leakage in the intake manifold. The air leakage levels are simulated as $20 \%$ of total air intake in the intake manifold. This fault occurs from the sample number 5401 to 5700 , see Figure 4.

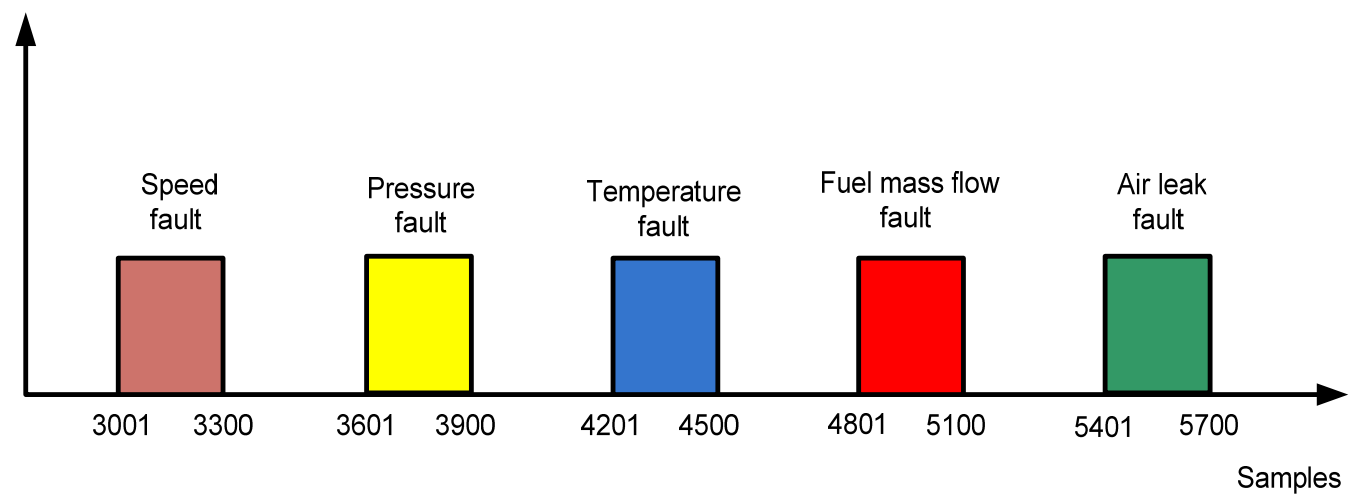

Figure 4. The simulated faults and sample number when they are present in the fault test data set.

B. Injected fuel mass Fault: For spark ignition (SI) engines, the target is to achieve an air-fuel mixture with a ratio of $14.7 \mathrm{~kg}$ air to $1 \mathrm{~kg}$ fuel. This means the normal value of air fuel ratio is 14.7 . This value will be changed if there are faults on the fuel injector and the amount of fuel. The value of fuel is reduced by $20 \%$ of the total fuel mass flow from sample number 4801 to 5100 , see Figure 4.

C. Speed, Temperature and Pressure Sensor Faults: Speed, pressure and temperature sensor faults considered are $10-20 \%$ change superimposed on the outputs of crankshaft speed, manifold pressure and temperature sensors. These faults are simulated from sample number 3001 to 3300 , from sample number 3601 to 3900 and from sample number 4201 to 4500 respectively. The faulty data for the sensors is generated using multiplying factors (MFs) of 1.1 and 1.2 for the above over -reading respectively, see Figure 4. Faulty data are generated by the Modified MVEM with throttle angle at different values between $20^{\circ}$ and $60^{\circ}$ for all the fault conditions. The 5 states with their multiplying factors (MFs) are given in table 1 . The sample time is chosen as $0.02 \mathrm{sec}$.

Table 1. The faults states and multiplying factors.

\begin{tabular}{ccc}
\hline No & Fault Name & MFs \\
$\mathbf{1}$ & Air Leak 20\% & \\
$\mathbf{2}$ & Injected fuel mass flow 20\% & \\
$\mathbf{3}$ & Speed sensor 10\% over reading & 1.1 \\
$\mathbf{4}$ & Pressure sensor 20\% over reading & 1.2 \\
$\mathbf{5}$ & Temp. sensor 10\% over reading & 1.1 \\
\hline
\end{tabular}

\section{Fault detection}

The Figure 5 shows the information flow of fault detection and isolation. The RBF neural network receives five inputs signals, the first three inputs signals are manifold pressure, temperature and crankshaft speed which containing fault information, and the second two inputs signals are the throttle angle and the fuel mass flow and has three outputs with each indicating one of the investigated states in table 1 . This neural network will use at the beginning only the first three rows of the MVEM output matrix 
which consists of signals values of manifold pressure, manifold temperature and crankshaft speed, all these three inputs contain sensor, component and actuator faults. The output of the neural network will be used as a target matrix, which means this neural network is an independent model. The flow chart for the fault detection and isolation is illustrated in Figure 6, steps 1 to 10.12 hidden nodes are chosen by k-means method. Width and weights are trained using $p$-nearest neighbours algorithms and the same data of $\mu, w(0), P(0)$ which were used to train neural network engine model are used here. The trained network is then tested for all faults occurring. Figure 7 shows the test results for fault detection for all faults (sensor, component and actuator) before filtering, it can be seen the errors are big. After the filtering operation the results were very good and the errors decreased, see Figure 8 . The filter operations are done by using equation (8) in order to improve the test results figures and remove any malformation may accurse in the figures.

$$
E_{A F}=X \times E_{A F-1}+Y \times E_{B F}
$$

Where, the $E_{A F}$ is the vector after filtering operation, $X$ and $Y$ chosen values, $X$ value should be complemented for $Y$ value, $E_{A F-1}$ is the past value of $E_{A F}$, and $E_{B F}$ is the vector before the filtering operation. The detection thresholds are chosen as $0.2,(+0.1,-$ 0.13 ) and 0.1 for crankshaft speed, manifold pressure and manifold temperature error signals respectively. High thresholds may lead to missed detections whilst low thresholds will cause false alarm. Figure 9 shows the residual error (re) which is generated by the equation (9).

$$
r e=\sqrt[2]{e n^{2}+e p^{2}+e t^{2}}
$$

Where $e_{n}, e_{p}$ and $e_{t}$ are the error vectors of the speed, pressure and temperature respectively between the engine model and the RBF neural network. Thresholds are chosen as 0.18 , If the residual greater than threshold that means the fault occurs.

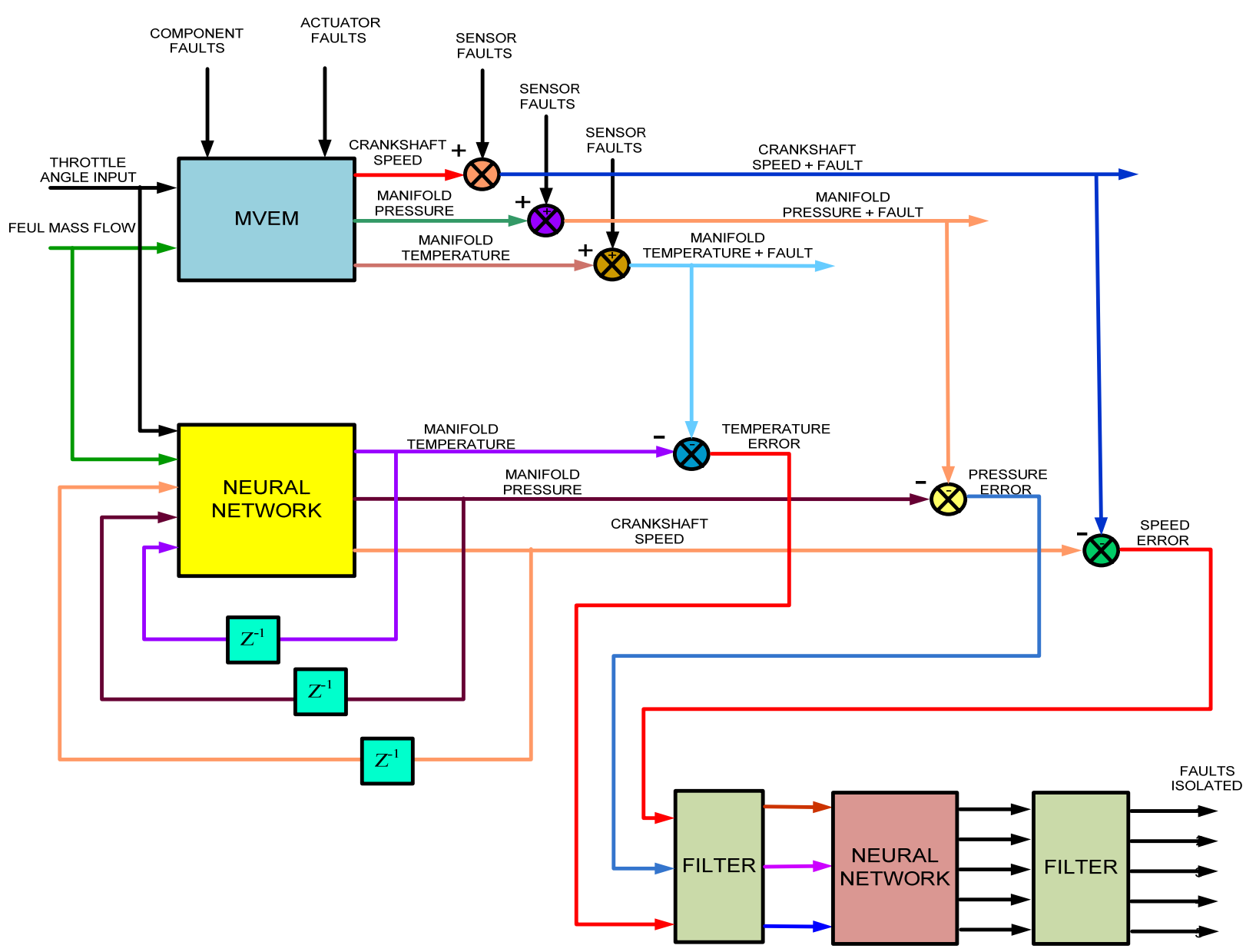

Figure 5. The information flow for the fault detection and isolation 


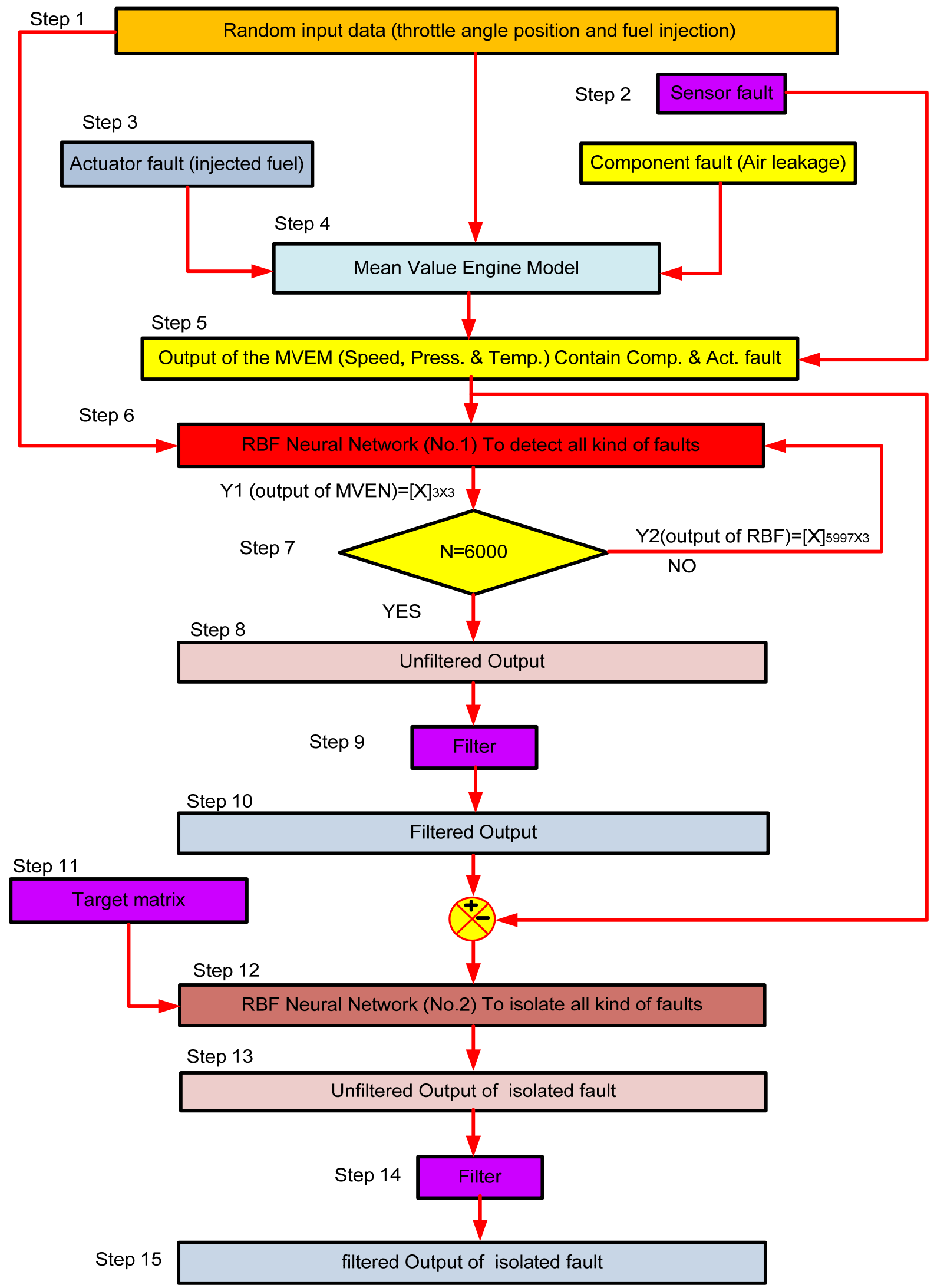

Figure 6. Flow chart of fault detection and isolation 


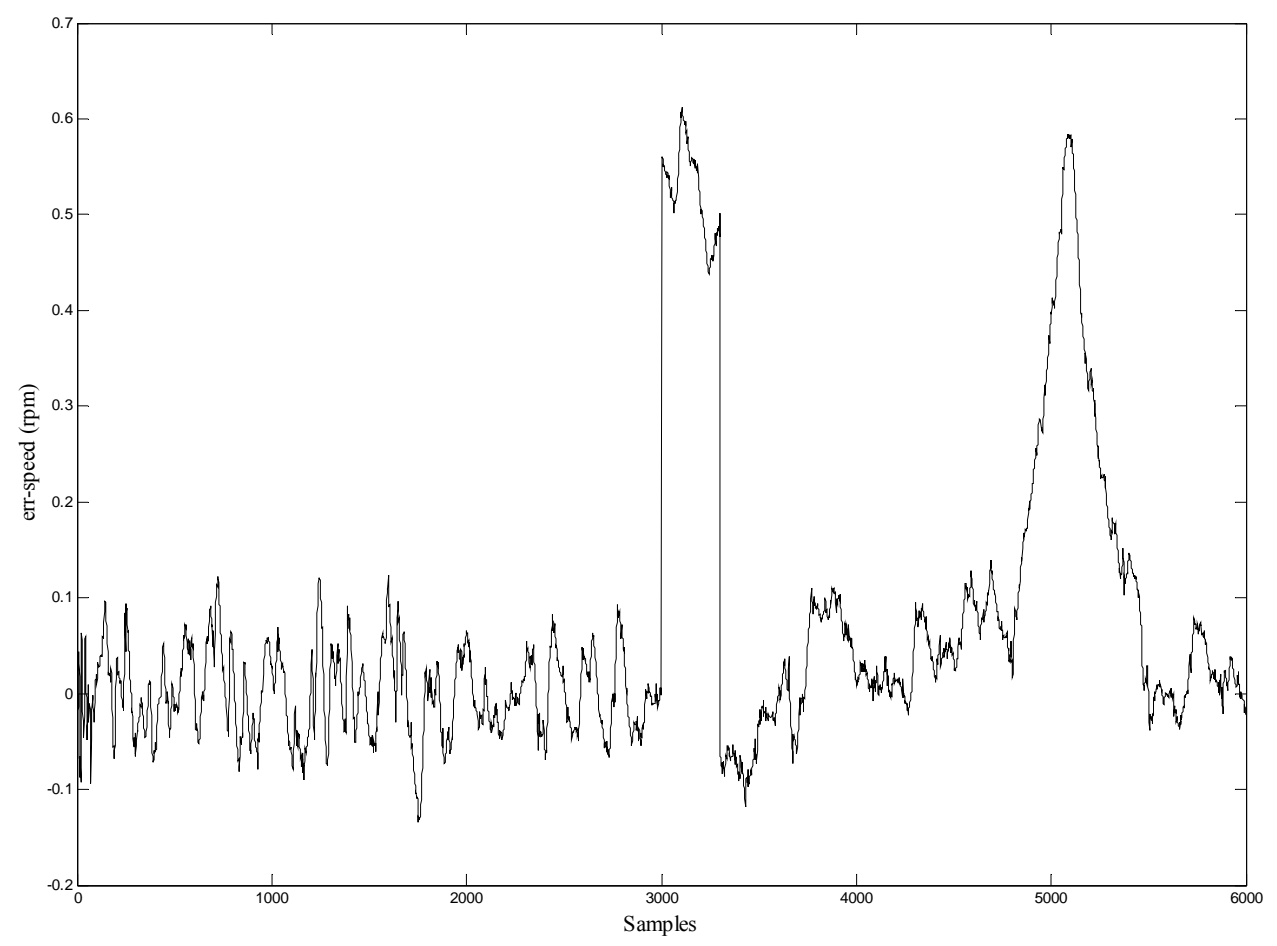

(a)

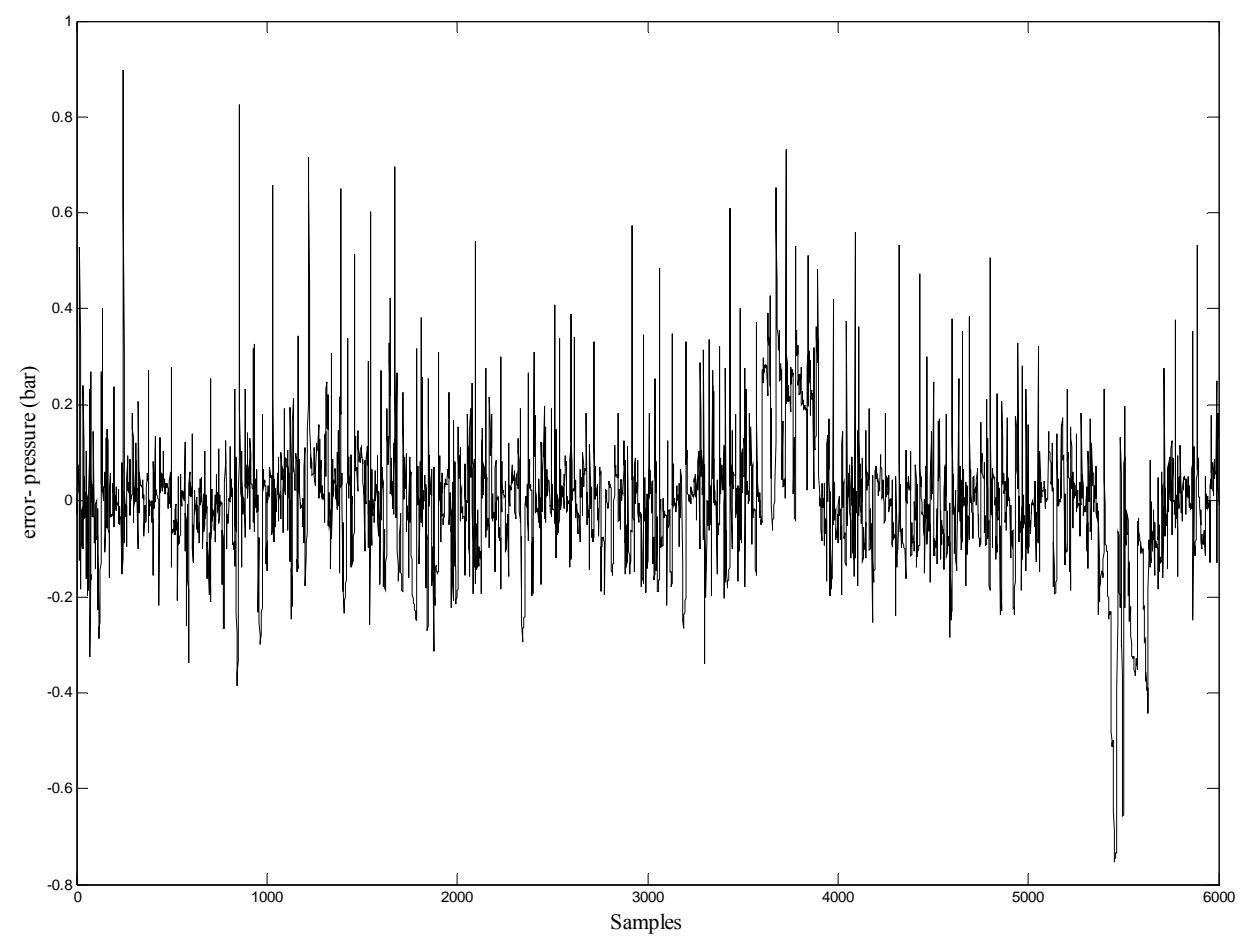

(b) 


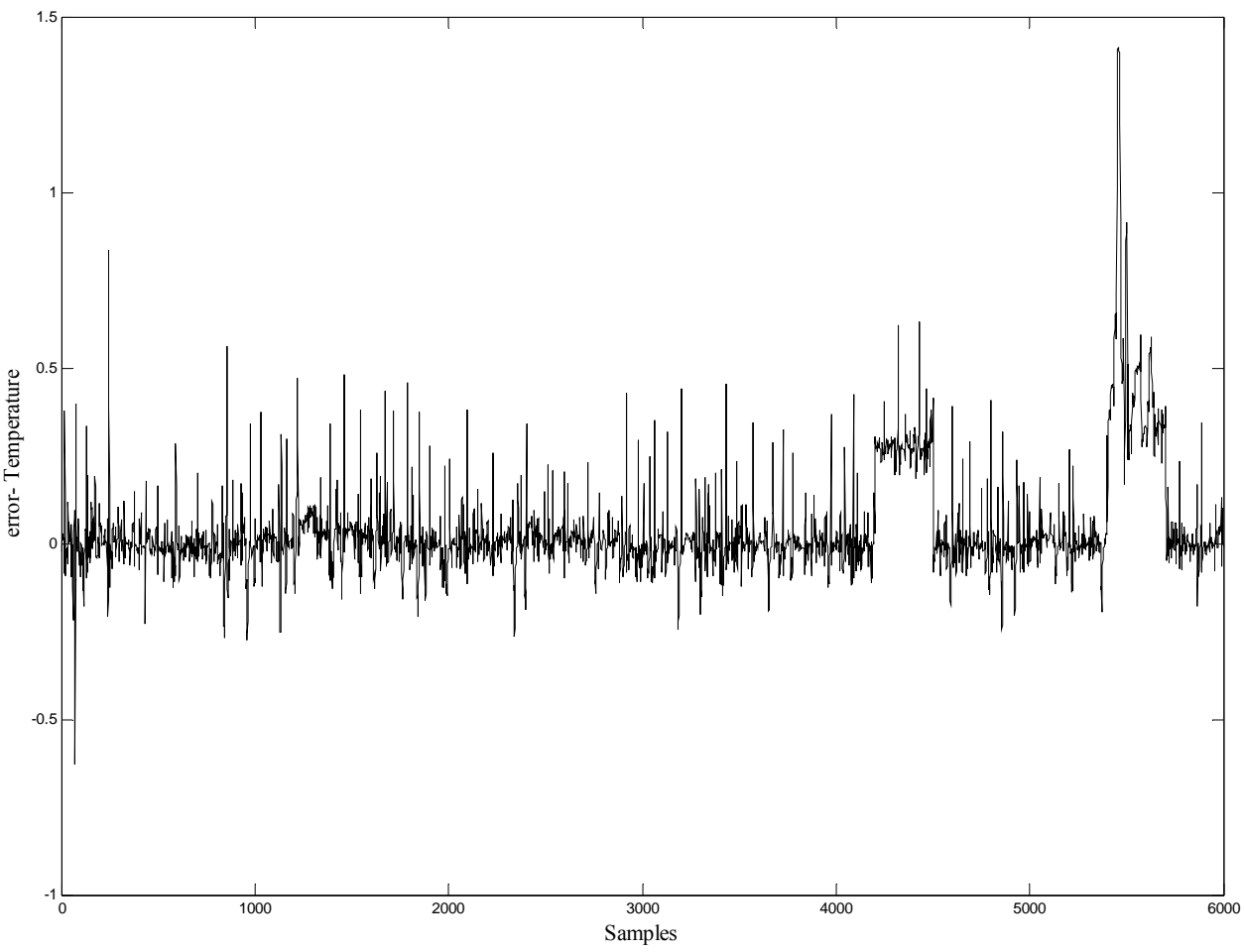

(c)

Figure 7. $\mathrm{a}, \mathrm{b}$ and $\mathrm{c}$. Test results of the fault detection of speed, pressure \& temperature respectively before filtering.

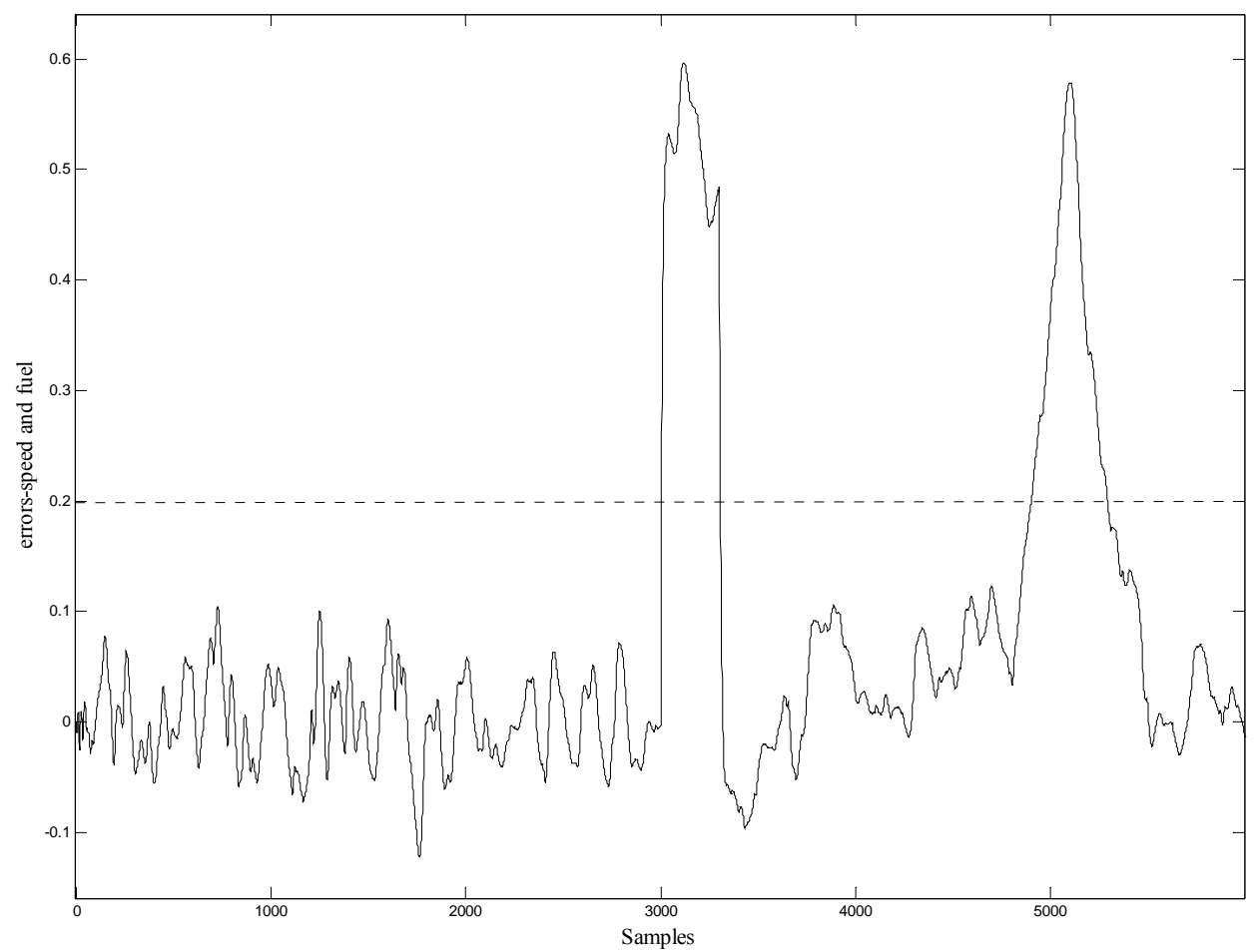

(a) 


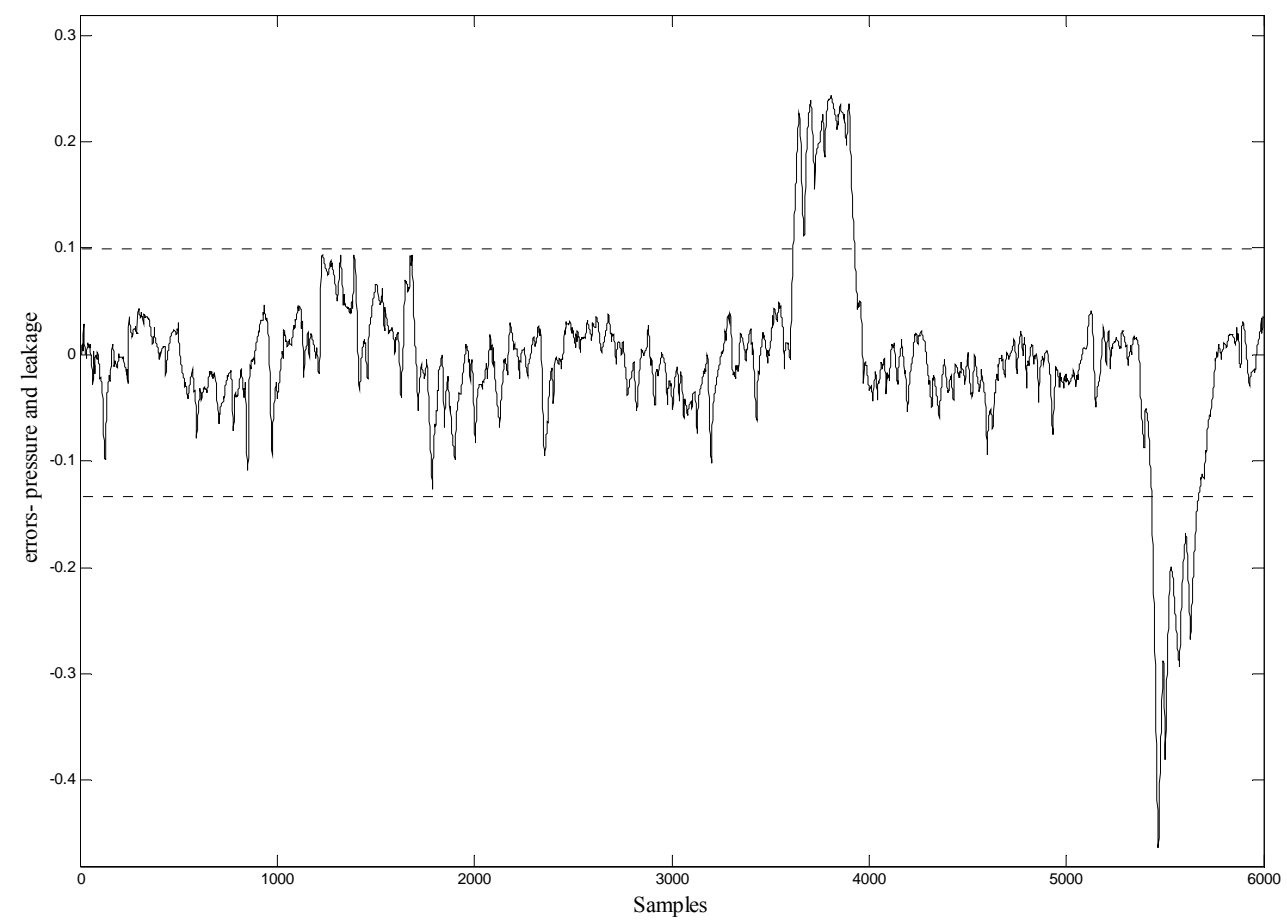

(b)

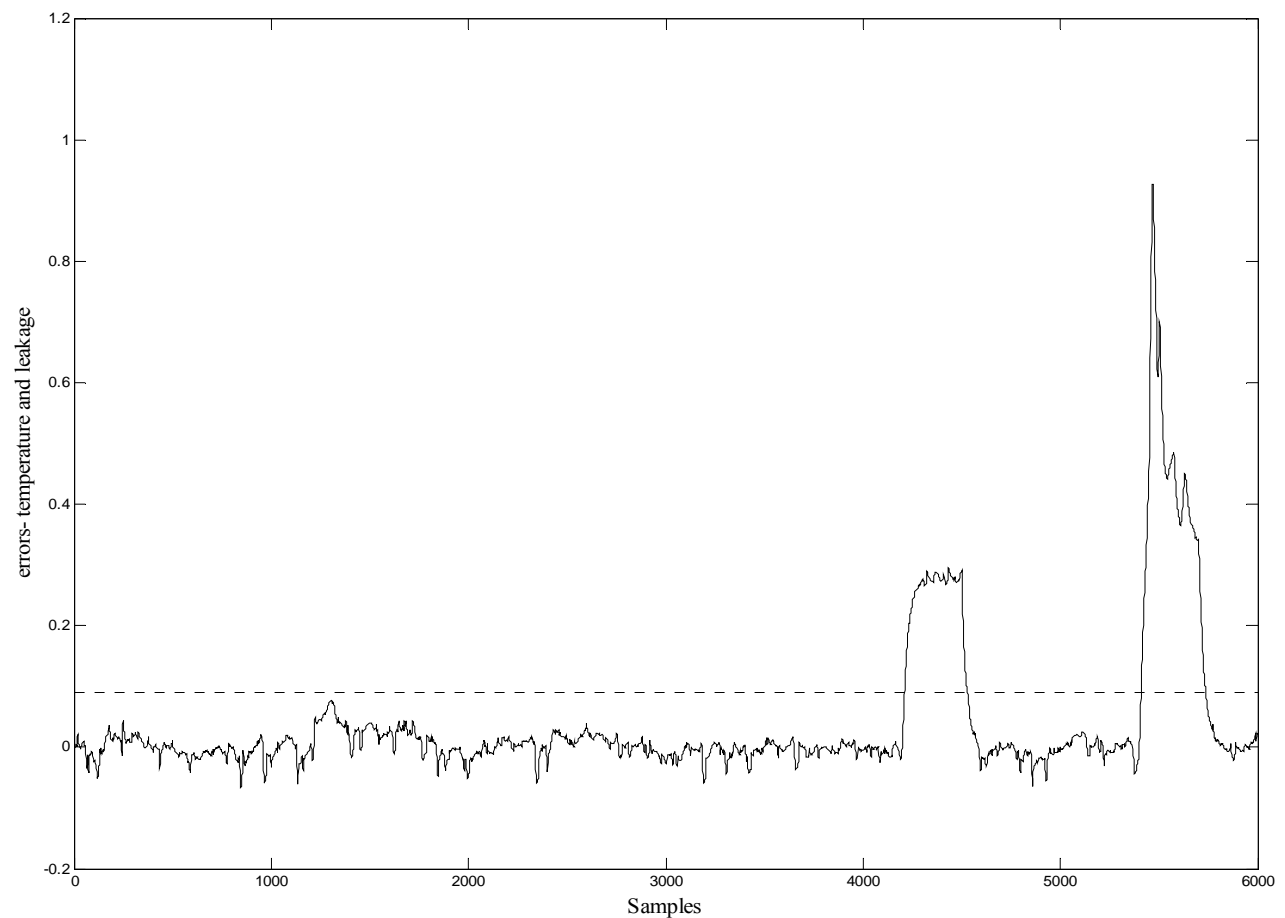

(c)

Figure 8. a, b, c. Test results of the fault detection of speed, pressure \& temperature respectively after filtering. 


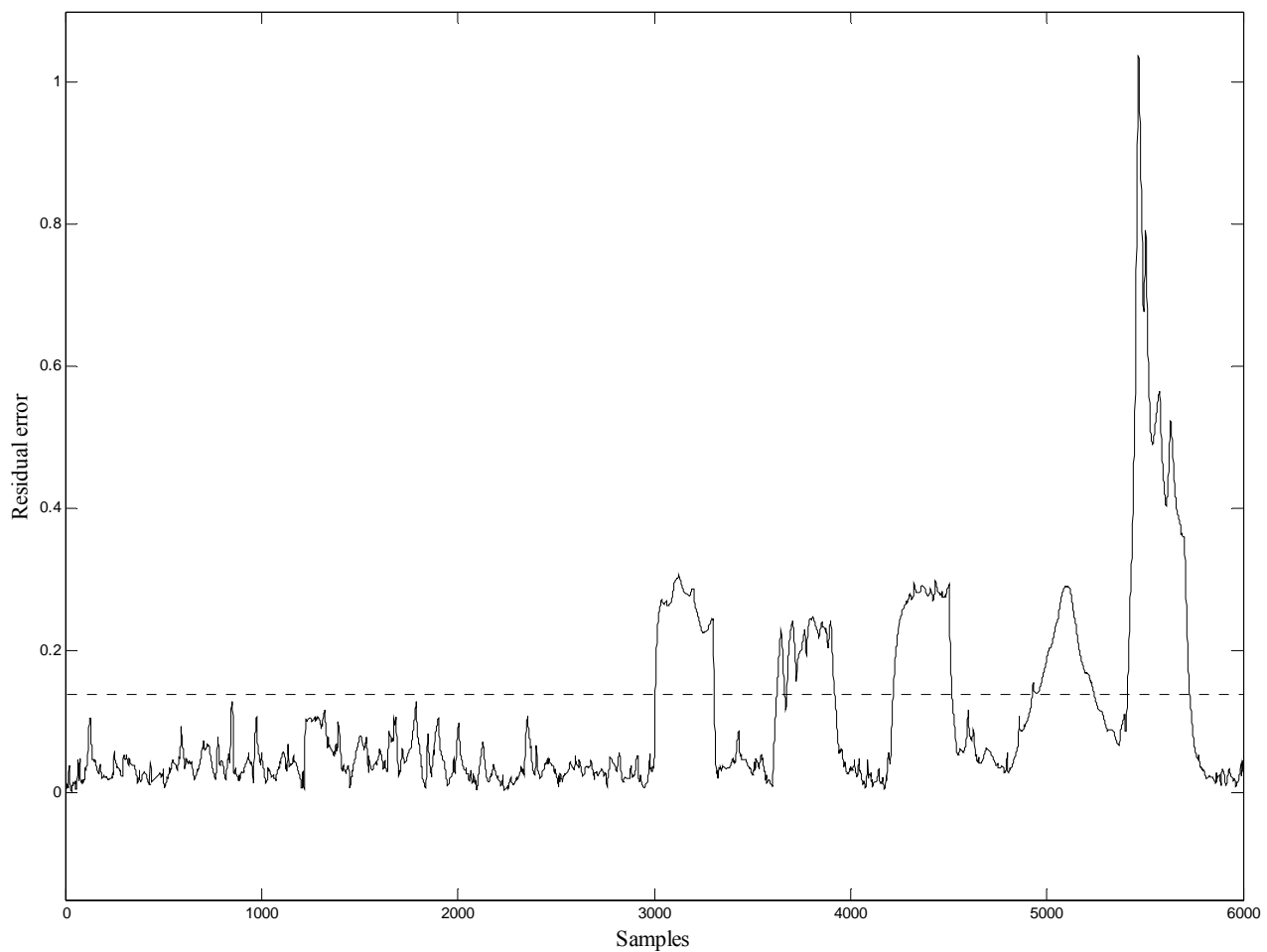

Figure 9. The residual error of the fault detection after filtering with 12 hidden nodes.

\section{Fault isolation}

The second RBF neural network will receive error signals which are the result signals between the MVEM model outputs and the first RBFNN outputs, see Figures 5 and 6 . Three variables are chosen as the network inputs: the error signals of crankshaft speed, manifold pressure and the manifold temperature. Two levels, 0 and 1 are used as the output target of the isolation. Thus, the target matrix is a unity diagonal matrix of dimension 5 with each column being used as the isolation training target vector. The target matrix has 6000 rows and 5 columns. From the first row to the $3000^{\text {th }}$ row, from the $3301^{\text {th }}$ row to the $3600^{\text {th }}$ row, from the $3901^{\text {th }}$ row to the $4200^{\text {th }}$ row, from the $4501^{\text {th }}$ row to the $4800^{\text {th }}$ row, from the $5101^{\text {th }}$ row to the $5400^{\text {th }}$ and from the $5701^{\text {th }}$ row to the $6000^{\text {th }}$ row have zeros, also this target matrix has ones in the first column from the $3001^{\text {th }}$ row to the $3300^{\text {th }}$ row, the second column from the $3601^{\text {th }}$ row to the $3900^{\text {th }}$ row, the third column from the $4201^{\text {th }}$ row to the $4500^{\text {th }}$ row, the fourth column from the $4801^{\text {th }}$ row to the $5100^{\text {th }}$ row, the fifth column from the $5401^{\text {th }}$ row to the $5700^{\text {th }}$ row and all the other entries are zeros, see Figure 10. Thus, the transpose of the $i^{\text {th }}$ row in $X_{0}$ is used as the training target vector for the $i^{\text {th }}$ training pattern. The width and weights are trained using $p$-nearest neighbours algorithms and the network weights with its parameters set are $\mu=1.0, w(0)=1.0 \times 10^{-6} \times U_{(n h \times 5)}$, $P(0)=1.0 \times 10^{5} \times I_{(\mathrm{nh})}$. Hidden nodes which were tried here are 50,100 and 200 by k-means method. The hidden nodes which are chosen here after the filtering operation are 50, this is because the test result is very good and similar to the cases of 100 and 200 hidden nodes and the size of neural network will be small, consequently the training and testing time will be small, Figure 11 and 12 show the test result before and after filtering. The isolation thresholds are chosen as 0.5 for all cases. 


\begin{tabular}{|c|c|c|c|c|c|c|c|}
\hline \multicolumn{3}{|c|}{ Row numbers } & \multicolumn{5}{|c|}{$\mathrm{X}_{0}$} \\
\hline 1 & to & 3000 & {$[0$} & 0 & 0 & 0 & 0 \\
\hline 3001 & to & 3300 & 1 & 0 & 0 & 0 & 0 \\
\hline 3301 & to & 3600 & 0 & 0 & 0 & 0 & 0 \\
\hline 3601 & to & 3900 & 0 & 1 & 0 & 0 & 0 \\
\hline 3901 & to & 4200 & 0 & 0 & 0 & 0 & 0 \\
\hline 4201 & to & 4500 & 0 & 0 & 1 & 0 & 0 \\
\hline 4501 & to & 4800 & 0 & 0 & 0 & 0 & 0 \\
\hline 4801 & to & 5100 & 0 & 0 & 0 & 1 & 0 \\
\hline 5101 & to & 5400 & 0 & 0 & 0 & 0 & 0 \\
\hline 5401 & to & 5700 & 0 & 0 & 0 & 0 & 1 \\
\hline 5701 & to & 6000 & 0 & 0 & 0 & 0 & 0 \\
\hline
\end{tabular}

Figure 10. The Target matrix $X$,

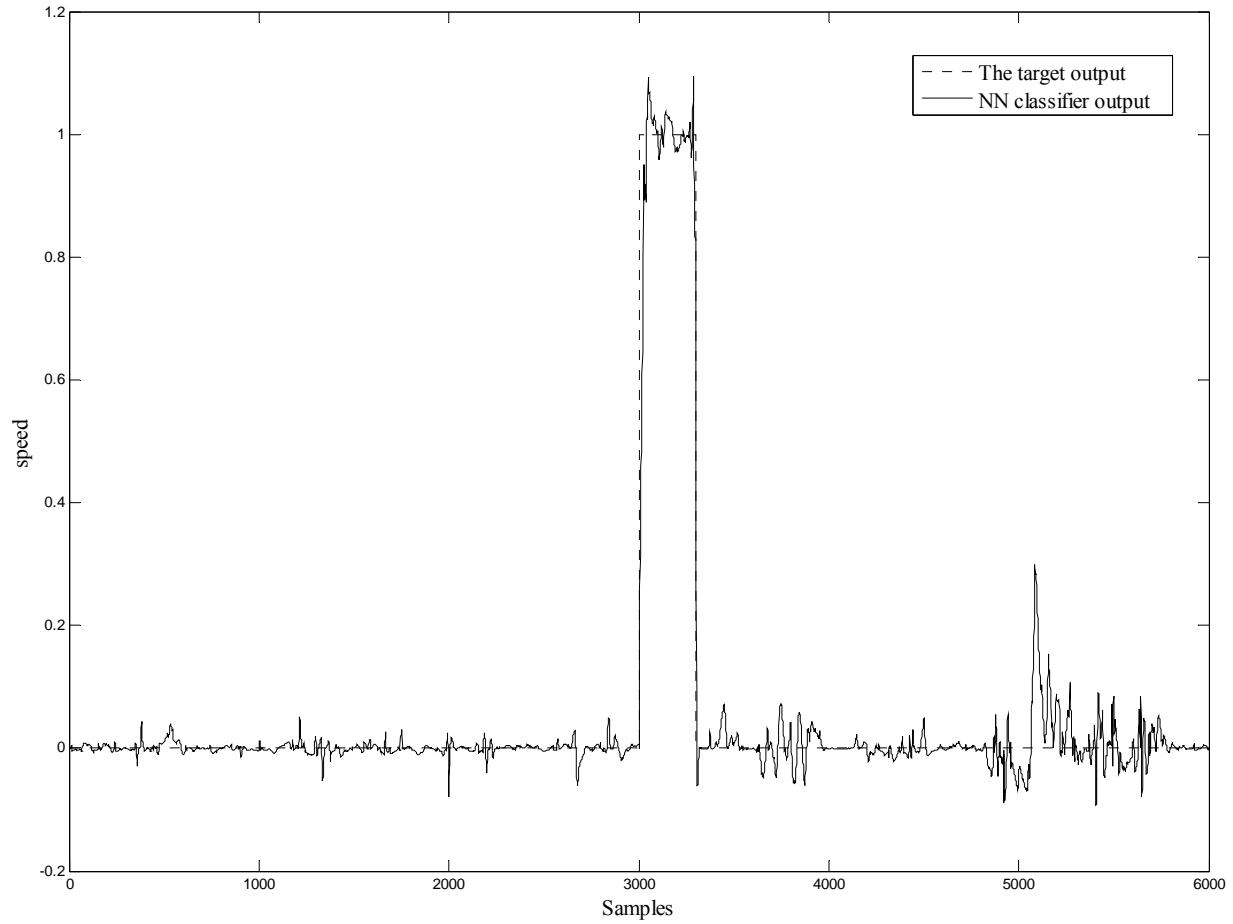

(a) 


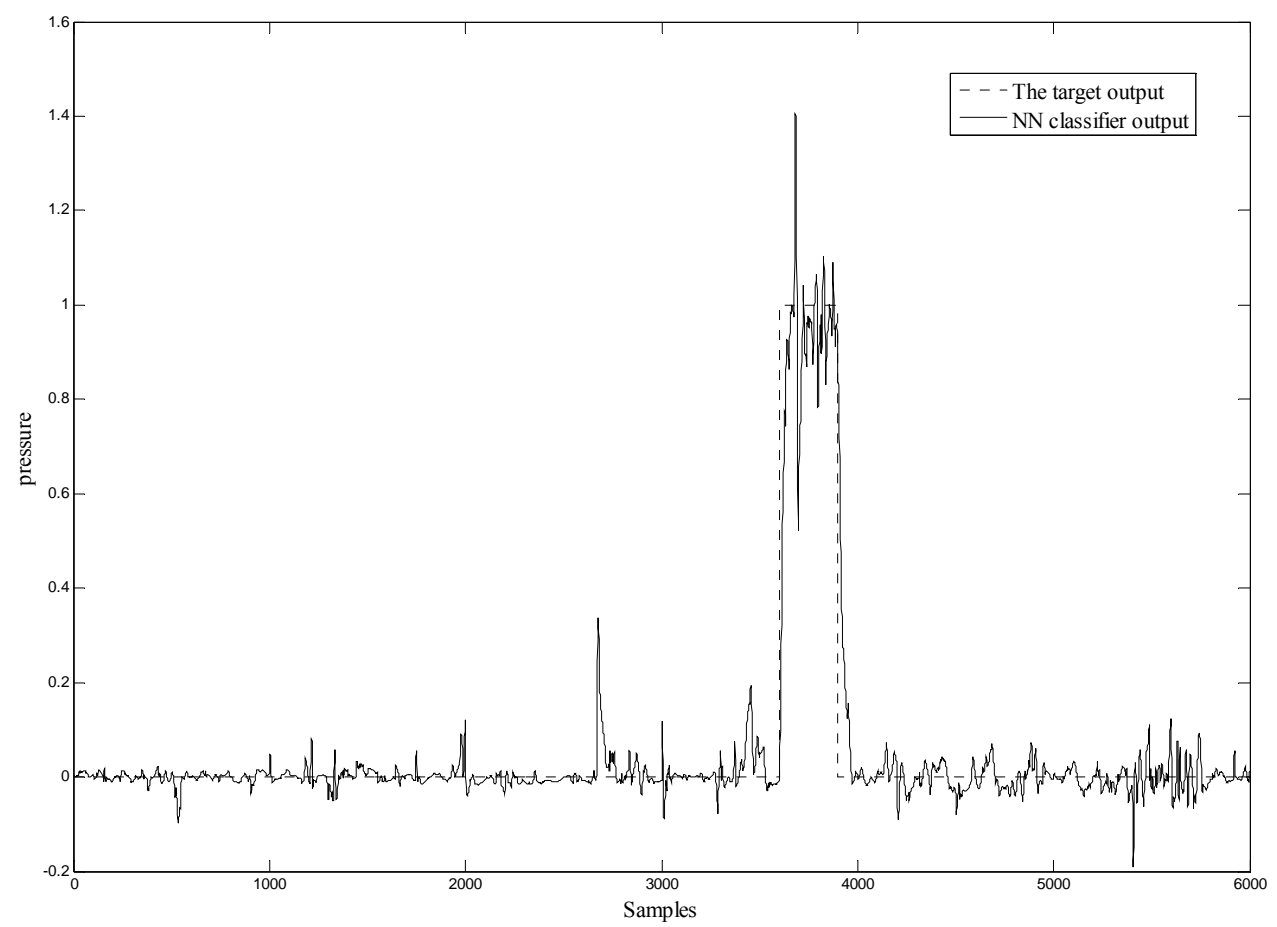

(b)

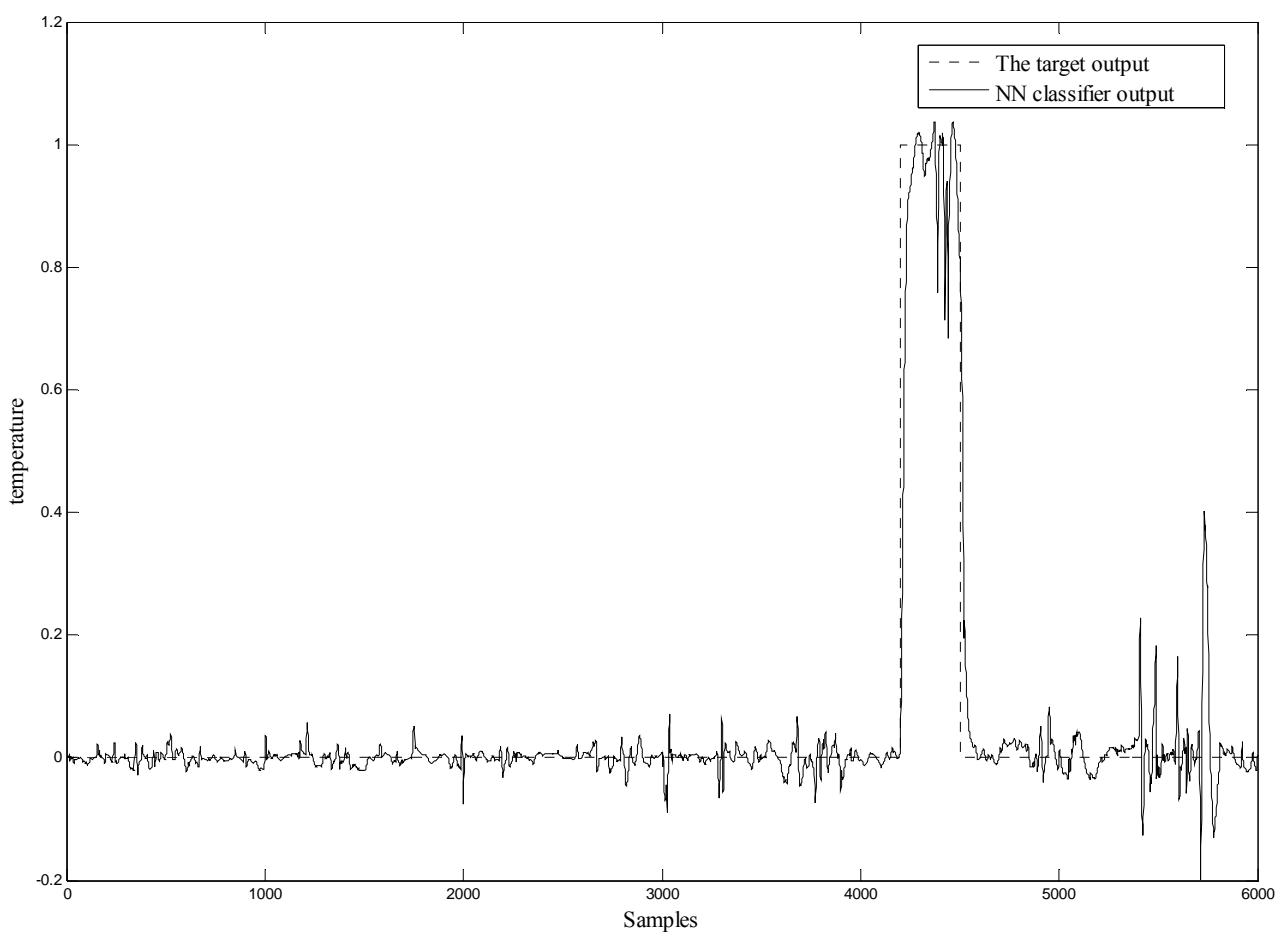

(c) 


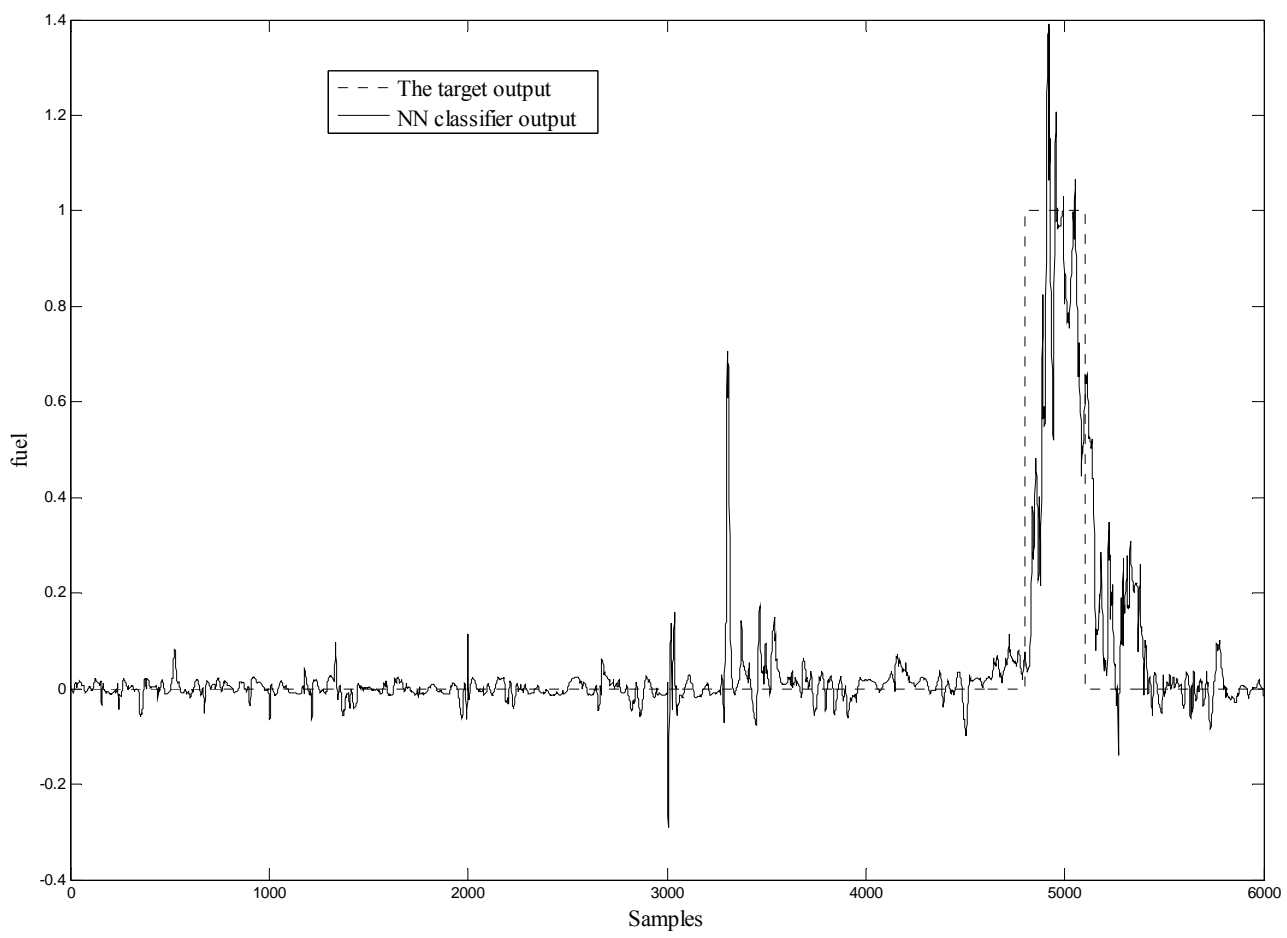

(d)

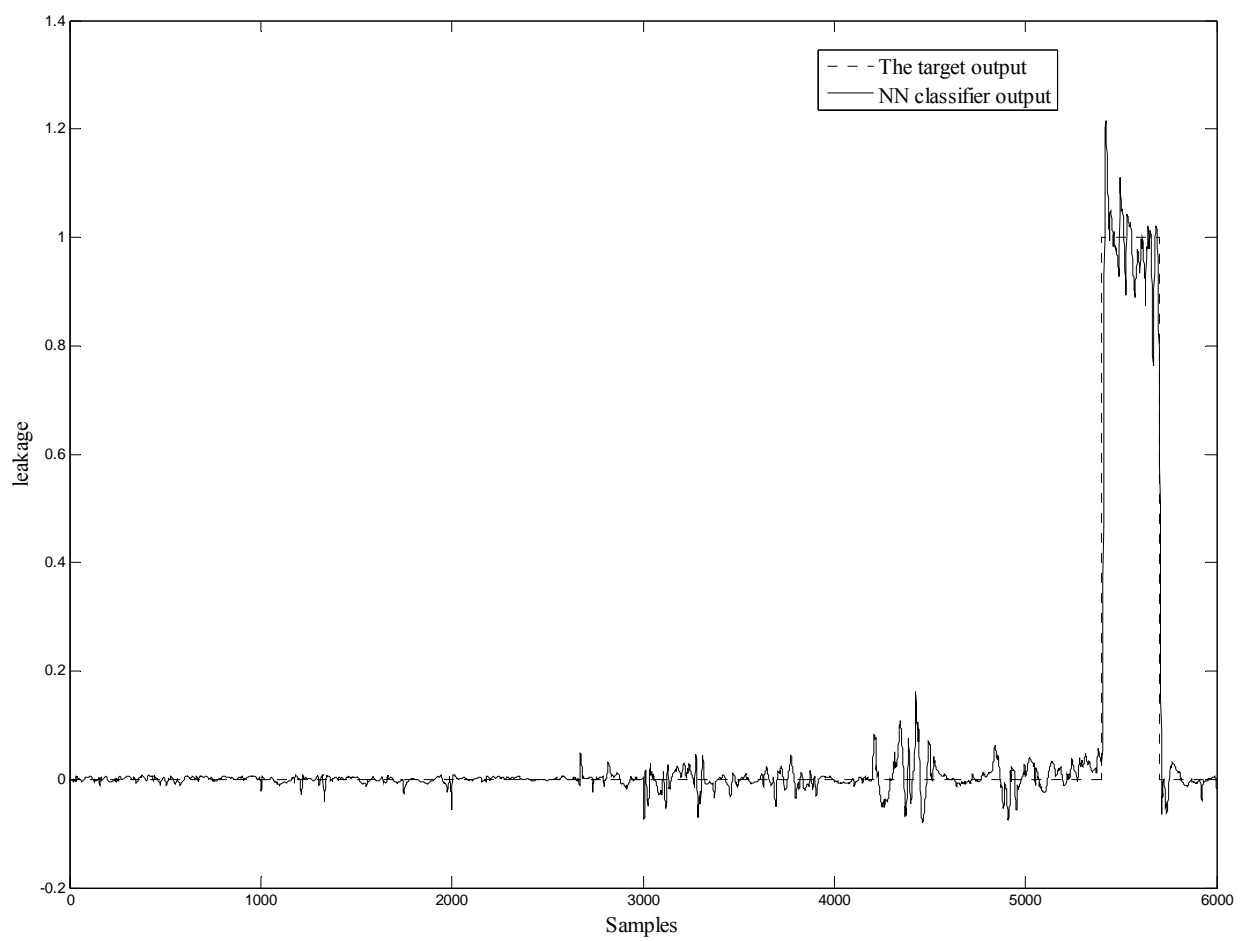

(e)

Figure 11,a, b, c, d \& e. Fault isolation result of speed, pressure ,temperature, fuel injection \& air leak respectively before filtering with 50 hidden nodes 


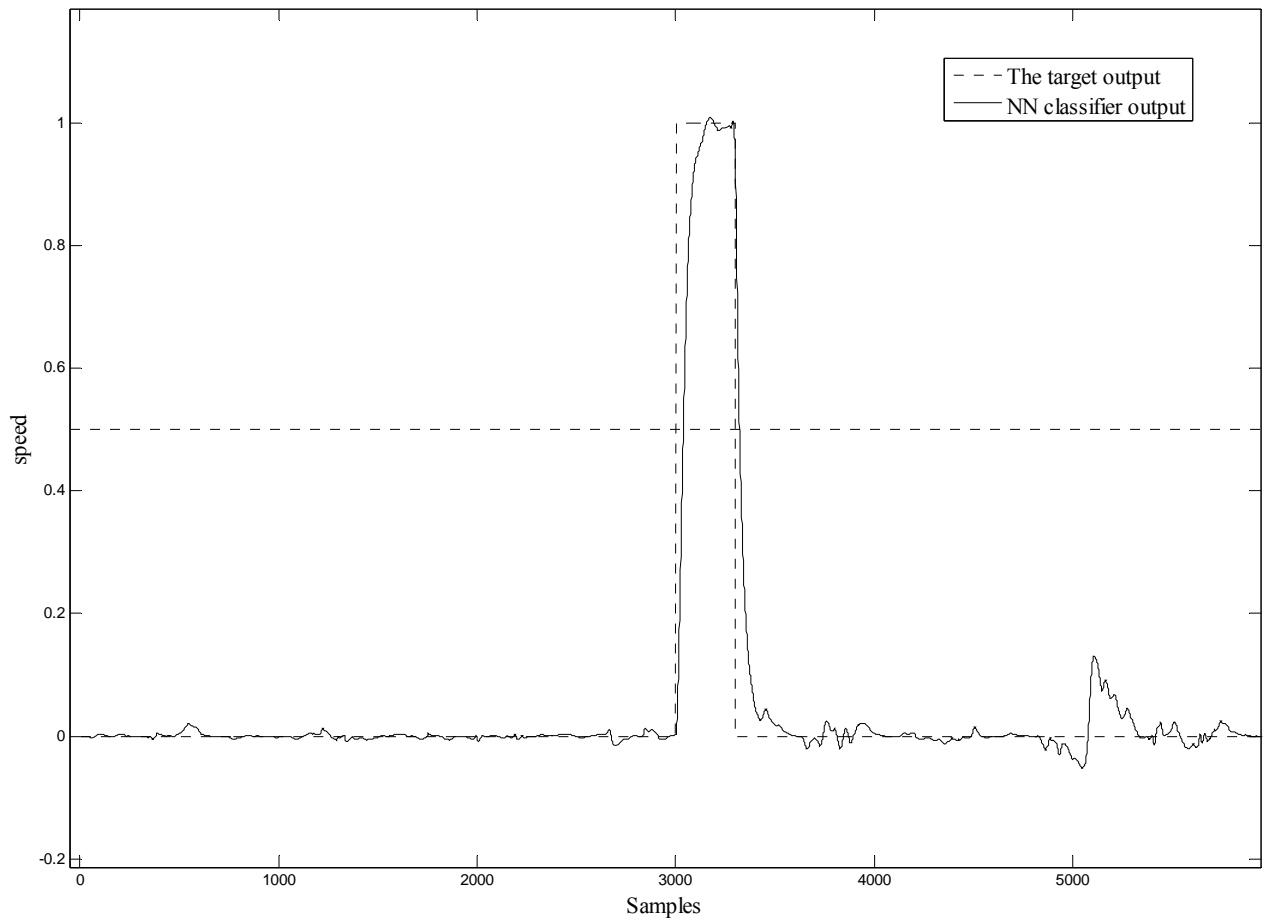

(a)

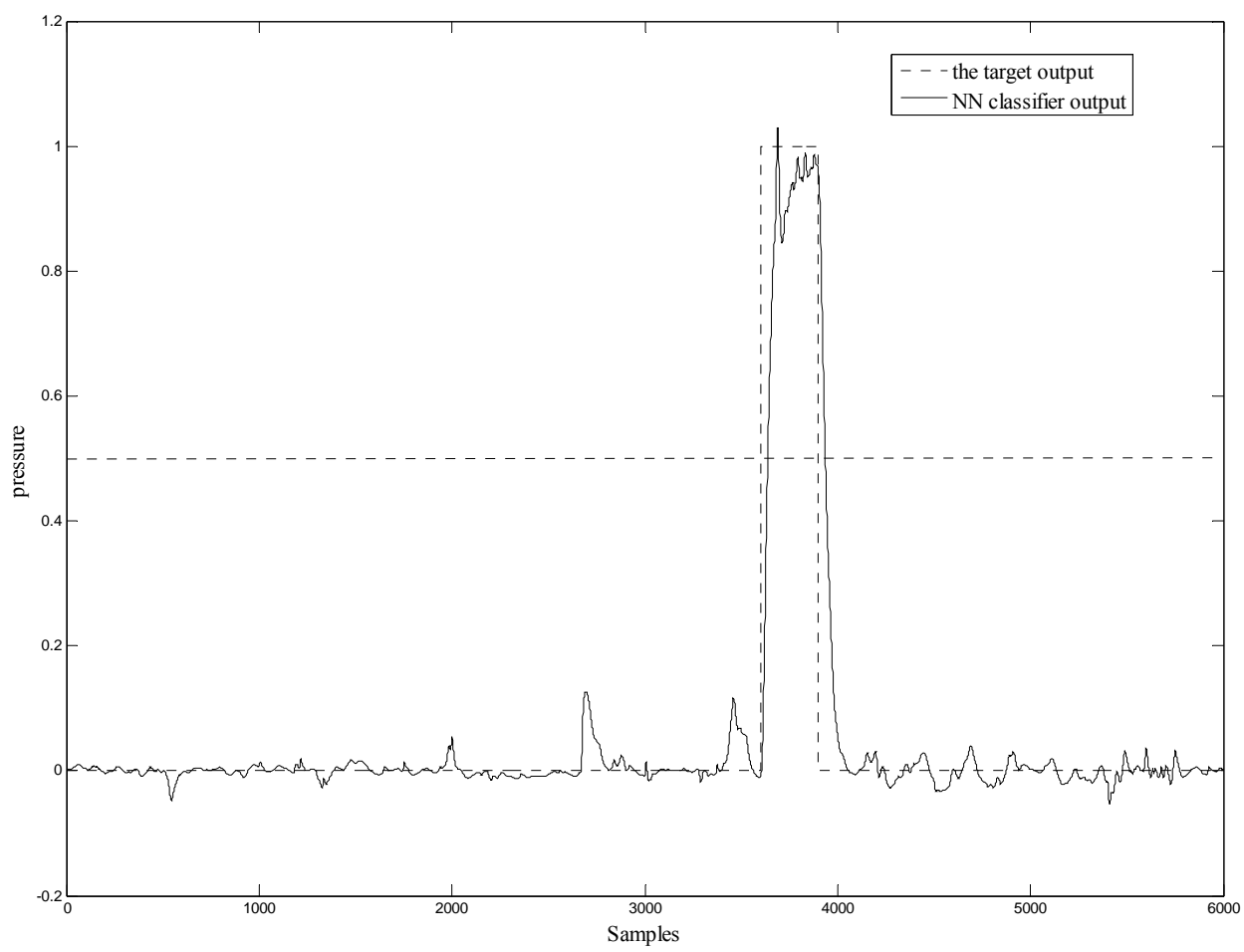

(b) 


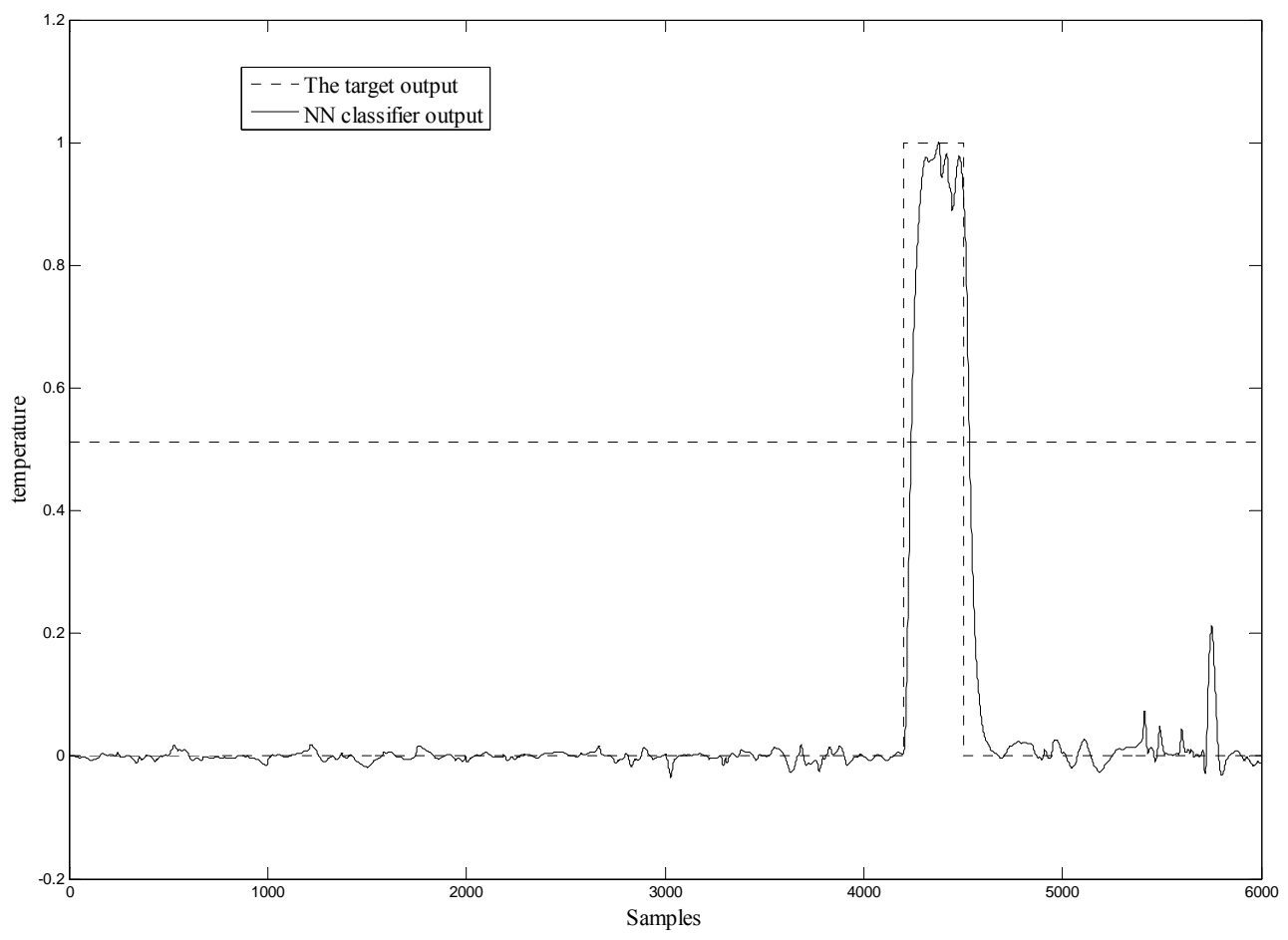

(c)

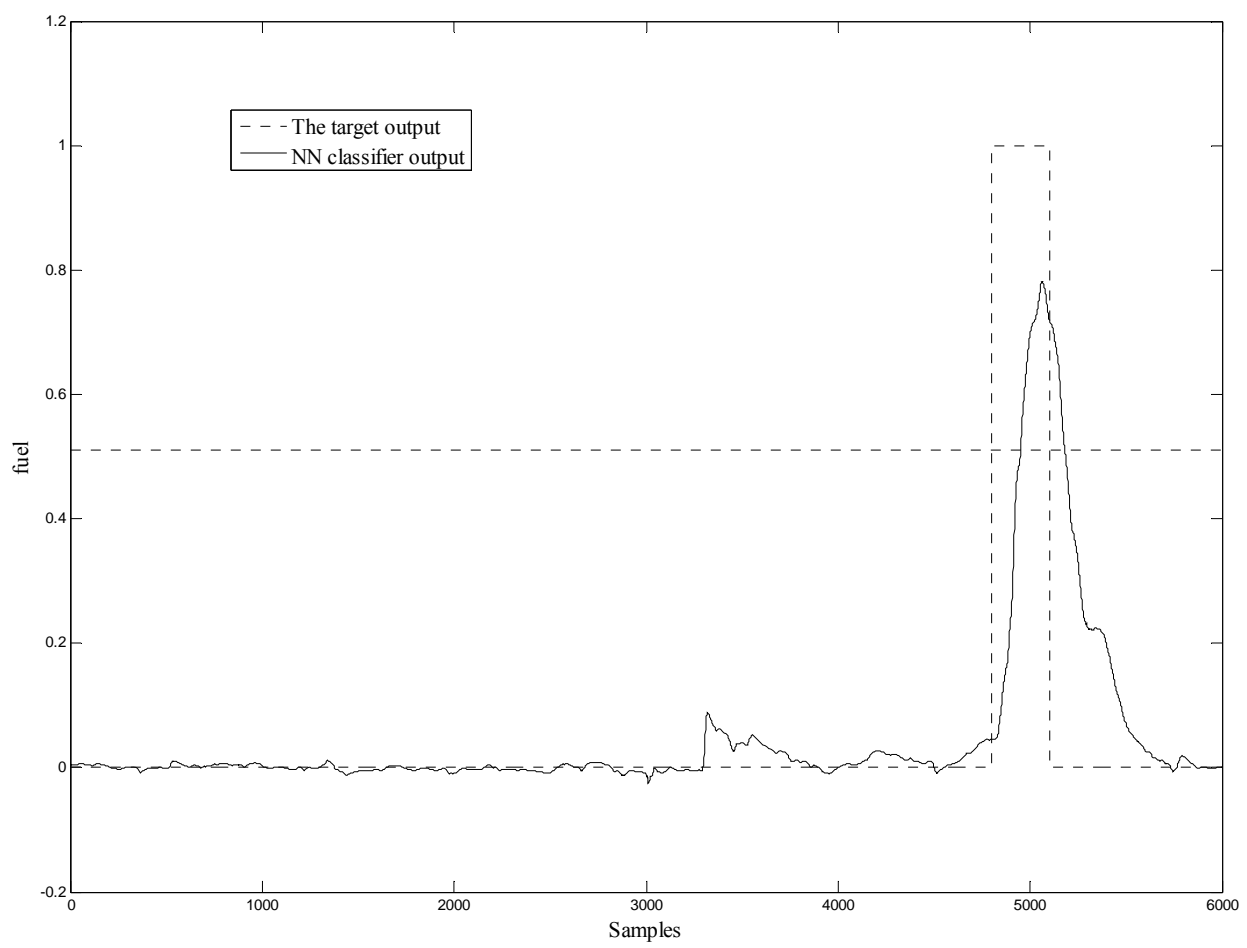

(d) 


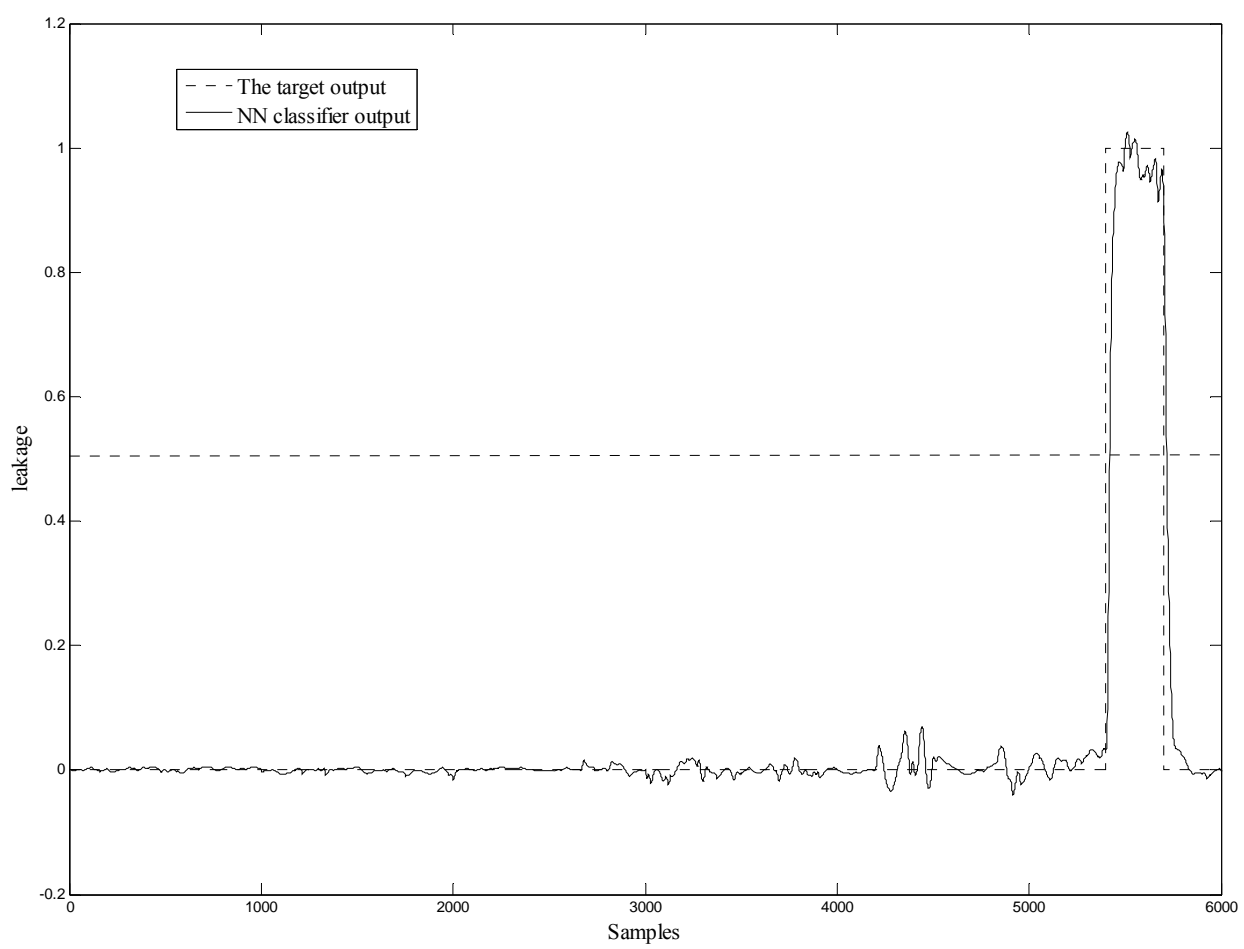

(e)

Figure 12,a, b, c, d \& e. Fault isolation result of speed, pressure ,temperature, fuel injection \& air leak respectively after filtering with 50 hidden nodes

\section{Simulation results}

The results can be summarized in the following points:

A. Training and Testing the Neural Network model: The simulation results of training and testing by using 12 hidden nodes were very good and in general, the good match between the engine model output and the RBF neural network output was achieved. From the Figure 3a it can be seen that the mean absolute error between the engine speed output and the RBFNN is very small, however it can be seen a mismatch in Figures $3 \mathrm{~b}$ and c, the mean absolute errors between the three outputs are shown in table 2.

Table 2. The Mean absolute error (MAE) between the engine model output and the RBF neural network output

\begin{tabular}{|c|c|}
\hline Outputs & $\begin{array}{c}\text { Mean Absolute } \\
\text { Errors }\end{array}$ \\
\hline Crankshaft speed & 0.0014 \\
\hline Pressure & 0.013 \\
\hline Temperature & 0.0047 \\
\hline
\end{tabular}

B. Detection of the Sensor, Components and Actuator Faults: The test results for fault detection for all kinds of faults were examined before and after the filtering operation by using the first RBFNN with 12 hidden nodes and all the faults were detected after filtering and were very clear. From the Figure 8, it can be seen the errors values were between - 0.1 and 0.15 except the samples in which faults occur. The detection thresholds were chosen as 0.2 for crankshaft speed, $(+0.1,-0.13)$ for manifold pressure and 0.1 for manifold temperature for scaled data.

C. Isolation of the Sensor, Components and Actuator Faults: In this section, another RBF neural network is used to isolate the faults. This neural classifier received residual error signals between the MVEM model outputs and the first RBFNN model outputs, and the target matrix is shown in Figure 10. To obtain good simulation results, 50, 100 and 200 hidden nodes were used. From the figures of the results, 50 hidden nodes after filtering operation were found the best situation and the simulated faults can be clearly isolated. This is because of the size of neural is small and training time were short. The isolation thresholds are chosen as 0.5 for all cases, see Figure 12. 


\section{Conclusions}

The mean value engine model (MVEM) developed by Hendricks (2000) is used for simulations during the research period after small modification. Expansion work has been done to the existing MVEM simulation by including air fuel ratio sensor time delay, temperature sensor dynamics etc. Three sensor faults (intake manifold pressure, temperature and speed), one component fault (leakage in the intake manifold) and one actuator fault (injected fuel mass flow) have been simulated when the simulation model is subjected to disturbances and noise. A RBF neural network model was used to model engine dynamics and the training algorithms are reviewed and derived. Another RBFNN classifier is used to isolate sensor faults, component fault and actuator fault from the modelling errors. By using $p$ - Nearest Neighbours method and K-means algorithm the width in hidden layer nodes of the RBF neural network $\sigma$ and the centres $\mathrm{c}$ are calculated for both RBFNNs. The recursive least square algorithm was applied for training the weights $w$ of the RBF neural networks. This method can detect and isolate dynamic faults, and this is because the modelling is for dynamic system, so can detect and isolate the faults in dynamic condition. From the simulation results it can be seen that both RBF neural networks were able to detect and classify all the faults clearly.

\section{References}

Balluchi A., Benvenuti, L., Benedetto Di, , Pinello MD., C., SangiovanninVincentelli, AL, 2000. Automotive engine control and hybrid systems: challenges and opportunities. Proceedings of the IEEE 88(7), pp. 888-912.

Blanke M.and Patton R.J., 1995. Industrial actuator benchmark for fault detection and isolation. Control Engineering Practice, Vol.3, No. 12, pp.1727-17307.

Capriglione D., and Pietrosanto A, June 2005. Real-Time Implementation of IFDIA Scheme in Automotive System. IEEE Transactions on Instrumentation and Measurement, Vol. 56, No. 3, pp.1667-1672.

Capriglione D, Liguori C, Pianese C, and Pietrosanto A, 2004. On-line sensor fault detection, isolation, and accommodation in automotive engines. IEEE transactions on instrumentation and measurement, Vol. 52, no. 4, august,pp.1182-1189.

Demetgul M., Tansel I.N., Taskin S., 2009. Fault diagnosis of pneumatic systems with artificial neural network algorithms. Expert Systems with Applications 36. pp. 10512-10519.

Hendricks, E., Engler, D. and Fam, M. 2000. A Generic Mean Value Engine Model for Spark Ignition Engines. In proceeding of $41^{\text {st }}$ simulation conference, Denmark,. DTU Lyngby.

Isermann, R. 2005. Model-based fault-detection and diagnosis status and applications. Annual Reviews in Control 29, pp 71-85.

Jamsa-Jounela S.-L., Vermasvuori M., Enden P., Haavisto S., 2003. A process monitoring system based on the Kohonen selforganizing maps. Control Engineering Practice, 11, pp. 83-92.

Wu J.D., Liu C.H., 2009. An expert system for fault diagnosis in internal combustion engines using wavelet packet transform and neural network. Expert Systems with Applications, vol. 36, pp. 4278-4286.

Kimmich F, Schwarte A and Isermann R, 2005. Fault detection for modern Diesel engines using signal- and process model-based methods. Control Engineering Practice 13, pp.189-203.

Mcfarlane D. C., 1996. A robust approach to dynamic statistical process control. Proceedings of 35th IEEE conference on decision and control, 11-13 Dec., Kobe, Japan, Vol. 3, pp.3113-14.

Nyberge M, Stutte T., 2004. Model based diagnosis of the air path of an automotive diesel engine. Control Engineering Practice, 12, pp. 513-525.

Sangha S. M., Dingli Yu and Gomm J. B., 2008. Robustness Assessment and Adaptive FDI for Car Engine. International Journal of Automation and Computing, April, pp. 109-118.

Sorsa T, Heikki N. K and Koivisto H, 1991. Neural networks in process fault diagnosis. IEEE Transactions on systems, man, and cybernetics, vol.21, no. 4, July/august.

Tan Y., Saif M., 2000. Neural-networks-based nonlinear dynamic modelling for automotive engines. Neurocomputing, 30, pp. 129-142.

Tsunglun Yu and Rizzoni G., 1991. A processor architecture for real-time fault detection and isolation in electronically controlled diesel engines.vehicular technology conference.

Wang S. W., D. L. Yu, Gomm J. B., Page G. F. and Douglas S. S, 2006. Adaptive neural network model based predictive control for air- fuel ratio of SI engines. Engineering Applications of Artificial Intelligence 19, Elsevier, pp. 189-200.

Zhai Y. J.and D. L Yu, 2007. Radial Basis Function Based Feeddback Control for Air Fuel Ratio of Spark Ignition. Proc. Instn mech. Engrs, part D: J. automobile engineering, Vol 222, pp. 415-428.

Biographical notes

Adnan Hamad received his B.Eng. degree in Electrical and Electronic Engineering from Bright Star University of Technology- Briga, Libya, in 1994. His M.s.c. in automatic control from Tabbin institute for metallurgical studies, Egypt, in 2006. He is now a PhD student in school of engineering at Liverpool John Moores University (LJMU), UK. His research interests include fault detection and isolation, process monitoring and neural network.

Professor Dingli Yu received B.Eng from Harbin Civil Engineering College, China in 1982, M.Sc from Jilin University of Technology (JUT), China in 1986, and 
the $\mathrm{PhD}$ from Coventry University, U.K. in 1995, all in Control Engineering. Dr. Yu was a lecturer at JUT from 1986 to 1990 , a visiting researcher at University of Salford, U.K. in 1991, a post-doctoral research fellow at Liverpool John Moores University (LJMU) from 1995 to 1998. He joined LJMU Engineering School in 1998 as a Senior Lecturer and was promoted to a Reader in 2003, then to Professor of Control Systems in 2006. He is the associate editor of two journals, International Journal of Modelling Identification and Control and International Journal of Information \& Systems Sciences. He organized two special issues in 2006, "Fault Detection, Diagnosis and Fault Tolerant Control for Dynamic Systems" and "Intelligent Monitoring and Control for Industrial systems". He serves as a member of the IFAC SAVEPROCESS Committee, and has been IPC member for many international conferences. He is a fellow of IET and Senior Member of IEEE. He leads the Control Systems Research group at LJMU. His current research interests include fault detection and fault tolerant control of bilinear and nonlinear systems, adaptive neural networks and their control applications, model predictive control for chemical processes and automotive engines and real-time evaluations, in these areas he has published more than 160 journal and conference papers.

J. Barry Gomm received the B. Eng. first class degree in electrical and electronic engineering in 1987 and the Ph. D. degree in process fault detection in 1991 from Liverpool John Moores University (LJMU), UK. He joined the academic staff at LJMU in 1991 and is a reader in intelligent control systems. His research interests include neural networks for modelling, control and fault diagnosis of non-linear processes, intelligent methods for control, system identification, adaptive systems, chemical process, and automotive applications.

M. S. Sangha is a widely experienced Chartered Engineer who is also a certified Six Sigma green belt. He received his BEng first class degree in electrical engineering in 1991 from Jai Narayan Vyas University, Jodhpur, India. He worked as an Electrical Engineer for the largest electricity distribution company (JVVNL) of Rajasthan State in India for about twelve years before perusing his Masters and PhD degrees from the UK. He received an MSc (Intelligent Control) with distinction in 2005 and subsequently a PhD degree in Intelligent Fault Diagnosis in 2008 from Liverpool John Moores University (LJMU), UK. He joined as Principal Engineer in Cummins Engine Co Ltd in 2008 where he is currently working. He is an Editorial Board Member of the International Journal of Engineering Science and Technology (IJEST). Currently he is managing a special issue for the Journal. He has published several research papers in international journals and conference proceedings. Dr Sangha is a member of the IET and IEEE, and has served as reviewer for several conferences. His current research interests include neural networks for modelling, control and fault diagnosis of non-linear processes, process optimization, adaptive neural networks, intelligent methods for control, system identification, supervisory control and data acquisition (SCADA).

Received December 2010

Accepted April 2011

Final acceptance in revised form July 2011 